\title{
Data assimilation of ground-level ozone in Europe with a Kalman filter and chemistry transport model
}

\author{
Remus G. Hanea \\ Faculty of Electrical Engineering, Mathematics and Computer Science, Department of Applied Mathematics, \\ Delft University of Technology, Delft, Netherlands \\ Netherlands Environmental Assessment Agency, Netherlands Institute of Public Health and the Environment (RIVM), \\ Bilthoven, Netherlands
}

\section{Guus J. M. Velders}

Netherlands Environmental Assessment Agency, Netherlands Institute of Public Health and the Environment (RIVM), Bilthoven, Netherlands

\section{Arnold Heemink}

Faculty of Electrical Engineering, Mathematics and Computer Science, Department of Applied Mathematics, Delft University of Technology, Delft, Netherlands

Received 24 October 2003; revised 11 March 2004; accepted 19 March 2004; published 20 May 2004.

[1] A Kalman filter coupled to the atmospheric chemistry transport model EUROS has been used to estimate the ozone concentrations in the boundary layer above Europe. Two Kalman filter algorithms, the reduced rank square root (RRSQRT) and the ensemble Kalman filter (ENKF), were implemented in this study. Both required, in general, a large number of EUROS model simulations for an assimilation. The observations consisted of hourly ozone data in a set of 135 ground-based stations in Europe for the period, June 1996. Half of these stations were used for the assimilation and the other half only for validation of the results. The combination between data assimilation (Kalman filter) and the atmospheric chemistry transport model, EUROS, gave more accurate results for boundary layer ozone than the EUROS model or measurements used separately. The average difference between assimilated and measured ozone concentrations decreased from 27.4 to $20.5 \mu \mathrm{g} \mathrm{m}^{-3}$ for the average of the stations used for validation in Europe. Both algorithms tend to converge to about the same accuracy, with an increasing number of EUROS model runs. About 10-20 EUROS model calculations were found sufficient for a good assimilation. The results are supported by a number of simulations that also reveal a local character for the assimilation process. INDEX TERMS: 3337 Meteorology and Atmospheric Dynamics: Numerical modeling and data assimilation; 3307 Meteorology and Atmospheric Dynamics: Boundary layer processes; 0345 Atmospheric Composition and Structure: Pollution — urban and regional (0305); 0368 Atmospheric Composition and Structure: Troposphere-constituent transport and chemistry; KEYWORDS: atmospheric $\mathrm{NO}_{\mathrm{x}}$, VOC

Citation: Hanea, R. G., G. J. M. Velders, and A. Heemink (2004), Data assimilation of ground-level ozone in Europe with a Kalman filter and chemistry transport model, J. Geophys. Res., 109, D10302, doi:10.1029/2003JD004283.

\section{Introduction}

[2] Elevated concentrations of ozone in the boundary layer can cause adverse affects to humans and ecosystems [e.g., European Communities (EC), 1996]. Ozone in the boundary layer is formed by chemical reactions of the ozone precursors, nitrogen oxides $\left(\mathrm{NO}_{\mathrm{x}}\right)$, volatile organic compounds (VOCs), and carbon monoxide and methane under the influence of sunlight. The impact of ozone is not limited to the area close to where the ozone precursors are emitted. Transboundary fluxes transport these precursors over distances of hundreds of kilometers [Lelieveld et al., 2002]. Atmospheric chemistry transport models have been devel-

Copyright 2004 by the American Geophysical Union. 0148-0227/04/2003JD004283\$09.00 oped to understand the processes controlling the formation of ozone, to study the potential effects of ozone on ecosystems and humans, and to assess the effects of emission reductions on the ozone concentration. Atmospheric models and observations are usually applied separately to obtain information about ozone and air pollutant concentrations in the boundary layer. Assimilating ozone observations in the model can improve the information on the state of the atmosphere. One method to assimilate measurement data into a model simulation to get a better estimate of the real ozone concentration is data assimilation.

[3] The most well-known application of this method has been in weather forecasting problems, in which data assimilation was applied in real-life applications for the first time [e.g., Ghil and Malanotte-Rizzoli, 1991; Courtier et al., 
1993]. The method has already proved to be useful in other fields of application like tidal models [Heemink and Kloosterhuis, 1990], or nonlinear shallow-water storm-surge models [Verlaan and Heemink, 1996]. In the last few years, data assimilation in atmospheric chemistry and transport modeling has received attention as well [e.g., van Loon and Heemink, 1997; Segers et al., 2000; Elbern et al., 1997, 2000; Wang et al., 2001]. The variational and sequential methods rank as two of the most well-known methods for applying data assimilation. Variational methods [Talagrand and Courtier, 1987] are based on the minimization of the cost function for the difference between the model and the measurements. The problem of minimizing this function is efficiently implemented by solving the adjoint problem. Elbern et al. [1997] implemented variational data assimilation using a 4D-var smoother technique for a tropospheric chemical transport model. The disadvantage of this method is the necessity of writing an adjoint model. For large-scale atmospheric transport problems implementation of an adjoint model is a very complicated task. From the beginning of 1980 s, the same time as the variational methods were introduced, sequential methods started to attract more and more attention [Ghil et al., 1981]. At first, Kalman filter techniques were used especially in oceanographic applications [Heemink and Kloosterhuis, 1990; Evensen, 1994]. The successful implementation of this method led to the introduction of similar techniques in related fields such as coastal hydrodynamics [Verlaan, 1998] and air pollution [e.g., Zhang and Heemink, 1995; Segers, 2002].

[4] Nevertheless, in the case of atmospheric transport models with a very large number of elements in the state vector, a filter approach with a full covariance matrix will be impossible to use. Several specific formulations of the Kalman filter technique were constructed to get pass this problem. These are called low-rank Kalman filter algorithms, and in this research are represented by the RRSQRT and ENKF. The performance of these two algorithms was tested by Canizares [1999] and compared in a twin experiment using a two-dimensional shallow-water equation model. In the move from the twin-experiment stage in the study by Zhang et al. [1999], the RRSQRT-filter was successfully used in real-life application to assimilate data into an atmospheric transport model in order to evaluate the $\mathrm{CH}_{4}$ budget in Europe. The model implemented for this research is a linear one and has no chemistry involved. In the study by Segers [2002] the RRSQRT and ENKF algorithms were used to estimate and predict ozone concentrations in an area of northwest Europe (England and Wales). The algorithm performance was tested on a smallscale atmospheric chemistry model. The grid consisted of $12 \times 12$ cells. The test period for assimilation was six days and the measurements taken from 11 rural sites.

[5] Important model errors in the case of ozone prediction are due to uncertainties in the emissions of pollutants. To take this into account, the $\mathrm{NO}_{\mathrm{x}}, \mathrm{VOC}$ and $\mathrm{CO}$ emissions in the study by Segers [2002] were considered as elements of the state vector and estimated by the Kalman filter technique. The results were promising and the data assimilation methods proved to be able to estimate the ozone concentrations in the case of a real-life small-scale atmospheric model. However, the methodology in this research field still has to be applied and modified for a real-life large-scale atmospheric model.
[6] In our study a Kalman filter approach using the same two low-rank algorithms (RRSQRT and ENKF) was developed to predict and estimate the ozone concentrations in combination with a large-scale atmospheric chemistry model (EUROS) above Europe. The EUROS model grid consists of $52 \times 54$ cells. The assimilation period was June 1996 and 135 ground-based observational sites spread all over Europe were used. A parameter estimation for the emissions of $\mathrm{NO}_{\mathrm{x}}$ and VOC, the photolysis rates of $\mathrm{NO}_{\mathrm{x}}$ and $\mathrm{O}_{3}$, and the deposition rate of $\mathrm{O}_{3}$ was performed, and the correction factors for all of the above parameters obtained. The emissions parameters and the deposition rates were also spatially defined for four large regions in Europe, chosen on the basis of their importance to the assimilation. The influence of these parameters on the performance of the assimilation was studied. The ultimate goal of the data assimilation was to obtain an optimal estimation of the real state of the atmosphere on the whole area and the corresponding model parameters needed for a parameter estimation tool.

[7] The Kalman filtering technique is discussed in section 2, as well as the implementation of the two algorithms. A short description of the EUROS model is given in section 3 , followed in section 4 by the definition of the statistical environment, and the observations used in the simulations. The results of the data assimilation calculations are presented and discussed in section 5 , i.e., the validation and general behavior of an assimilation, the performance of the two algorithms, convergence with the number of modes, effects of the randomness in the ENKF algorithm, effects of the number and location of the observations, and effects of the specification of the noise parameters. The conclusions are given in section 6 .

\section{Kalman Filtering}

\subsection{State Space Model}

[8] Kalman filtering represents the link between a model and measurements. This technique processes the measurements in a physically consistent way, taking into account the model. This is achieved by extending the deterministic model represented by

$$
x^{t}\left(t_{k+1}\right)=M\left(x^{t}\left(t_{k}\right)\right),
$$

to a stochastic model

$$
x^{t}\left(t_{k+1}\right)=M\left(x^{t}\left(t_{k}\right)\right)+w\left(t_{k}\right),
$$

where $M\left(x^{t}\left(t_{k}\right)\right)$ represents one time step of the numerical model and $w\left(t_{k}\right)$ is the white-noise process: $w\left(t_{k}\right) \sim N(0$, $\left.Q\left(t_{k}\right)\right)$. The covariance matrix $Q\left(t_{k}\right)$ is supposed to be of low rank so that it can be factorized as $Q\left(t_{k}\right)=Q\left(t_{k}\right)^{1 / 2}\left[Q\left(t_{k}\right)^{1 / 2}\right]^{T}$, where $Q\left(t_{k}\right)^{1 / 2}$ is a matrix with a small number of columns. This vector quantifies the uncertainties in the model that need to be specified.

[9] The state space representation in this research was based on an augmented state vector described in detail in section 4. All the available data for time $t_{k}$ are stored in a vector $\mathrm{y}^{\mathrm{o}}\left(\mathrm{t}_{\mathrm{k}}\right)$. The "true" data or the "true" values measured without errors are related to the true state according to a linear observation model,

$$
y^{o}\left(t_{k}\right)=H\left(t_{k}\right) x^{t}\left(t_{k}\right)
$$


Through the observation model operator $H$, a forecast for the observed data locations can be made from the forecast of the state. Uncertainties in the measurements need to be specified as well. Therefore the vector $y^{o}$ from equation (3) is expanded as follows:

$$
y^{o}\left(t_{k}\right)=H\left(t_{k}\right) x^{t}\left(t_{k}\right)+v\left(t_{k}\right)
$$

where the observations linear operator $H\left(t_{k}\right)$ assigns the ozone concentration for the observation height of a grid cell to an observation and $v\left(t_{k}\right)$ is the observation noise process: $v\left(t_{k}\right) \sim N\left(0, R\left(t_{k}\right)\right)$.

\subsection{Extended Kalman Filter For Nonlinear Systems}

[10] The idea is to combine the measurements modeled by equation (4) with the information provided by the atmospheric model in order to obtain an optimal estimation of the state of the system. The first step in a Kalman filter algorithm is to specify the initial distribution of the true state

$$
x^{t}\left(t_{0}\right) \sim N\left(x^{f}\left(t_{0}\right), P^{f}\left(t_{0}\right)\right) .
$$

The second step, the forecast step, defines the evolution of the distribution of the true state:

$$
\begin{gathered}
x^{f}\left(t_{k+1}\right)=E\left(x^{t}\left(t_{k+1}\right)\right)=\mathbf{M}\left(t_{k}\right) x^{t}\left(t_{k}\right) \\
P^{f}\left(t_{k+1}\right)=E\left[\left(x^{t}\left(t_{k+1}\right)-x^{f}\left(t_{k+1}\right)\right)\left(x^{t}\left(t_{k+1}\right)-x^{f}\left(t_{k+1}\right)\right)^{T}\right] \\
=\mathbf{M}\left(t_{k}\right) P^{f}\left(t_{k}\right) \mathbf{M}\left(t_{k}\right)^{T}+Q\left(t_{k}\right)
\end{gathered}
$$

where

$$
\mathbf{M}\left(t_{k}\right)_{i j}=\frac{\partial M_{i}\left(x^{f}\left(t_{k}\right)\right)}{\partial x_{j}^{f}\left(t_{k}\right)}
$$

represents the tangent linear model. In general, the applicability of the forecast model strongly depends on the assumption of weak nonlinearity of the model.

[11] The third step, the analysis step, in the filter algorithm is the analysis of the available data. If measurements are available at a certain time the mean and the covariance are replaced by analyzed equivalents given the new information

$$
x^{a}\left(t_{k}\right)=x^{f}\left(t_{k}\right)+K\left(t_{k}\right)\left(y^{o}\left(t_{k}\right)-H\left(t_{k}\right) x^{f}\left(t_{k}\right)\right)
$$

$P^{a}\left(t_{k}\right)=\left[I-K\left(t_{k}\right) H\left(t_{k}\right)\right] P^{f}\left(t_{k}\right)\left[I-K\left(t_{k}\right) H\left(t_{k}\right)\right]^{T}+K\left(t_{k}\right) R\left(t_{k}\right) K^{T}\left(t_{k}\right)$

where the Kalman gain $K\left(t_{k}\right)$ is calculated by

$$
K\left(t_{k}\right)=P^{f}\left(t_{k}\right) H\left(t_{k}\right)^{T}\left[H\left(t_{k}\right) P^{f}\left(t_{k}\right) H\left(t_{k}\right)^{T}+R\left(t_{k}\right)\right]^{-1} .
$$

These are the general equations for conventional Kalman filtering for nonlinear systems. Using these equations in an atmospheric chemistry transport model with nonlinear processes and with a large grid involves certain problems. $P^{a}\left(t_{k}\right)$ is very big (high computation time) and is ill conditioned [Heemink et al., 2001]; that is, there is a large range of eigenvalues. Furthermore the tangent linear model given by equation (8) must be used. To solve these problems, one needs to use some low-rank Kalman filter has to be used suitable for data assimilation in models with large state vectors. Two algorithms are used for this in combination with the EUROS model: the reduced rank square root Kalman filter (RRSQRT) and ensemble Kalman filter (ENKF).

\subsection{Ensemble Kalman Filter}

[12] The ensemble Kalman filter was introduced by Evensen [1994] and has been successfully used in many applications [Evensen and van Leeuwen, 1996; Houtekamer and Mitchell, 1998]. This Monte Carlo approach is based on the representation of the probability density of the state estimate in an ensemble of possible states, $\xi_{1}, \xi_{2}, \xi_{3} \ldots \xi_{N}$. Each ensemble member is assumed to be a single sample out of a distribution of the true state. Whenever necessary, statistical moments are approximated with sample statistics. Thus the ensemble Kalman filter algorithm is based on a representation of the probability density of the state estimate by a finite number of $N$ randomly generated system states (also called modes).

[13] In the first step of this algorithm an ensemble of $N$ states $\xi_{i}^{a}\left(t_{0}\right)$ is generated to represent the uncertainty in $x\left(t_{0}\right)$. In the second step, the forecast step, the stochastic model propagates the distribution of the true state:

$$
\begin{gathered}
\xi_{i}^{f}\left(t_{k}\right)=M\left(\xi_{i}^{a}\left(t_{k-1}\right)\right)+w_{i}\left(t_{k}\right) \\
x^{f}\left(t_{k}\right)=\frac{1}{N} \sum_{i=1}^{N} \xi_{i}^{f}\left(t_{k}\right) \\
E^{t}\left(t_{k}\right)=\left[\xi_{1}^{f}\left(t_{k}\right)-x^{f}\left(t_{k}\right), \xi_{2}^{f}\left(t_{k}\right)-x^{f}\left(t_{k}\right), \ldots, \xi_{N}^{f}\left(t_{k}\right)-x^{f}\left(t_{k}\right)\right]
\end{gathered}
$$

When the measurements become available the mean and the covariance are replaced with equivalent ones in the analysis step using

$$
\begin{gathered}
P^{f}\left(t_{k}\right)=\frac{1}{N-1} E^{f}\left(t_{k}\right) E^{f}\left(t_{k}\right)^{T} \\
K\left(t_{k}\right)=P^{f}\left(t_{k}\right) H\left(t_{k}\right)^{T}\left[H\left(t_{k}\right) P^{f}\left(t_{k}\right) H\left(t_{k}\right)^{T}+R\left(t_{k}\right)\right]^{-1} \\
\xi_{i}^{a}\left(t_{k}\right)=\xi_{i}^{f}\left(t_{k}\right)+K\left(t_{k}\right)\left[y^{o}\left(t_{k}\right)-H\left(t_{k}\right) \xi_{i}^{f}\left(t_{k}\right)+v_{i}\left(t_{k}\right)\right]
\end{gathered}
$$

where the ensemble of state vectors is generated with the realizations $w_{i}\left(t_{k}\right)$ and $v_{i}\left(t_{k}\right)$ of the noise processes $w\left(t_{k}\right)$ and $v\left(t_{k}\right)$, respectively. The advantages of this algorithm are that $P^{f}$ is positive definite and that the linear tangent model is not required any more because the ensembles are propagated through the model using the original operator as in equation (11) (first equation). Also, in the final implementation of the algorithm, $P^{f}\left(t_{k}\right)$ need not be computed [Evensen, 1994]. For most practical problems the forecast equation (first equation from equation (11)) is computationally dominant [Dee, 1991]. As a result, the computational effort required for the ENKF is approximately $N$ model simulations. The standard deviation of the errors in the state estimate is of a statistical nature and converges very slowly with the number of ensembles. This 
is a disadvantage of a Monte Carlo approach. Here it should be noted that for many atmospheric data assimilation problems the analysis step is also a time consuming part of the algorithm [Houtekamer and Mitchell, 1998].

\subsection{Reduced Rank Square Root Kalman Filter}

[14] Another approach for solving large-scale Kalman filtering problems is to approximate the full covariance matrix of the state estimate by a matrix with a reduced rank. This approach was introduced by Cohn and Todling [1995] and Verlaan and Heemink [1995, 1996]. Algorithms based on similar ideas have been applied by Pham et al. [1998]. The reduced-rank approach can also be formulated as an ENKF where the $q$ ensemble members are not chosen randomly, but in the direction of the $q$ leading eigenvectors of the covariance matrix [Verlaan and Heemink, 1996]. This algorithm can be applied and implemented in case of the matrix $P^{a}\left(t_{k}\right)$ is a low-rank matrix. Because of the fact that few models parameters were assumed to be uncertain and because of the dispersion in the model we can assume that $P^{a}$ is low rank in our case. The algorithm approximates the error covariance $P^{f, a}\left(t_{k}\right)$ for forecast and analysis by

$$
P^{f, a}=\left(V^{f, a}\right)\left(D^{f, a}\right)\left(V^{f, a}\right)^{T},
$$

where $V^{f, a}\left(t_{k}\right)$ contains the eigenvectors of the covariance matrix and $D^{f, a}\left(t_{k}\right)$ is the diagonal matrix with eigenvalues on the diagonal. The square root of $P^{f, a}$ is denoted by

$$
L^{f, a}=\left(V^{f, a}\right)\left(D^{f, a}\right)^{1 / 2}
$$

So $L^{f, a}\left(t_{k}\right)$ will be an $n \times q$ matrix because it will take the first $q$ eigenvalues of the matrix. Now the reduced rank square root algorithm can be summarized as follows. In the time step the time propagation of the estimate and of the error covariance take place according to

$$
x^{f}\left(t_{k+1}\right)=M\left(t_{k}\right) x^{a}\left(t_{k}\right)
$$

$P^{f, a}\left(t_{k+1}\right)=\left(L^{f, a}\right)\left(L^{f, a}\right)^{T} \Rightarrow L^{f, a}\left(t_{k+1}\right)=\left[M\left(t_{k}\right) L^{f \cdot a}\left(t_{k}\right), Q^{1 / 2}\left(t_{k}\right)\right]$

The addition of columns every time step, represented by $Q^{1 / 2}$ for the noise, would increase the computation time.

[15] The second step in the algorithm is the reduction step: The idea is to use only the first $q$ leading eigenvalues and eigenvectors of the approximated covariance matrix $P^{f, a}$. It is known that $\left(L^{f, a}\right)\left(L^{f, a}\right)^{T}$ has the same eigenvalues as the matrix $\left(L^{f, a}\right)^{T}\left(L^{f, a}\right)$ and that is why a singular-value decomposition is carried out

$$
\left(L^{f, a}\right)^{T}\left(L^{f, a}\right)=\left(U^{f, a}\right)\left(D^{f, a}\right)\left(U^{f, a}\right)^{T} .
$$

This method places the eigenvalues in decreasing order and can also prove that the eigenvectors of $\mathrm{P}^{\mathrm{f}, \mathrm{a}}$ are given by the columns of the matrix $\left(L^{f, a}\right)\left(U^{f, a}\right)\left(D^{f, a}\right)^{-1 / 2}$. The actual computation is then given by the eigenvalue decomposition of equation (16) followed by a reduction like

$$
L^{* f, a}=\left(L^{f, a}\right)\left(U^{f, a}\right)_{1: n, 1: q}
$$

Here ()$_{1: n, 1: q}$ denotes the truncation of the number of columns to $q$.

[16] The third step is the measurement update when observations are available. Several of the measurement update equations known in literature do not depend on the specific type of square root. Here is presented the scalar update of J. E. Potter [Maybeck, 1979]:

$$
\begin{gathered}
\Psi\left(t_{k+1}\right)=L^{* f, a}\left(t_{k}\right) H\left(t_{k}\right) \\
\gamma\left(t_{k+1}\right)=\Psi\left(t_{k+1}\right)^{T} \Psi\left(t_{k+1}\right)+R\left(t_{k+1}\right)^{-1} \\
K^{R R}=L^{* f, a}\left(t_{k+1}\right) \Psi\left(t_{k+1}\right) \gamma\left(t_{k+1}\right) \\
L^{a}\left(t_{k+1}\right)=L^{* f, a}\left(t_{k+1}\right)-K^{R R} \Psi\left(t_{k+1}\right)^{T}\left[1+\gamma\left(t_{k+1}\right) R\left(t_{k+1}\right)^{1 / 2}\right]^{-1}
\end{gathered}
$$

Independent measurements can be processed one at a time. The most time-consuming part of the RRSQRT algorithm is the propagation of the modes (equation (15)), since for each mode the model should be called up once. Therefore the reduction step must reduce the number of modes as much as possible, but at the same time it must keep the important information in the covariance matrix. The advantage of this algorithm is that the original model operator is used for the calculations and that the characteristic of a positive definite $P^{f}$ is preserved.

[17] The Kalman filter is implemented in a modular way around the EUROS model. The EUROS model is called as a subroutine from the Kalman filter routines. The interface between the EUROS model and the Kalman filter consists only of a number of parameters (the state vector and model noise) exchanged between both by a call to the subroutine (i.e., the EUROS model). So changes to the model (e.g., updates) do not affect the Kalman filter routines and are therefore easily implemented in the code.

\section{Eulerian Chemistry Transport Model EUROS}

[18] The Eulerian atmospheric chemistry transport model European Operational Smog (EUROS) [van Rheineck Leyssius et al., 1990; van Pul et al., 1996; Matthijsen et al., 2001] was developed at the National Institute of Public Health and the Environment (RIVM), Netherlands. The model contains parameterizations of the various chemical, dynamical and radiative processes in the atmosphere, as well as information about the emissions of ozone precursors, nitrogen oxides, VOCs, carbon monoxide and methane. The model can be used to examine the time and spatial behavior of $\mathrm{SO}_{\mathrm{x}}, \mathrm{NO}_{\mathrm{x}}, \mathrm{O}_{3}$, and VOCs in the lower troposphere over Europe.

\subsection{Domain and Processes}

[19] The model area extends over a large part of Europe and uses a shifted pole coordinate system; that is, the real North Pole is at $30^{\circ}$ northern latitude, and the equator has been shifted to $60^{\circ}$ northern latitude in the new coordinate system. In these shifted pole coordinates the model domain is $\left[-8.25^{\circ}, 20.35^{\circ}\right] \times\left[-23.1^{\circ}, 7.15^{\circ}\right]$. The grid consists of $52 \times 55$ grid cells with a longitude-latitude resolution of $0.55^{\circ} \times 0.55^{\circ}$ (about $60 \times 60 \mathrm{~km}$ ). The vertical stratification of EUROS consists of four layers from the surface up to 
$3000 \mathrm{~m}$. The height of the layers varies during the day because of meteorological processes. The surface layer is defined as the lowest $50 \mathrm{~m}$ of the atmosphere. In this layer, emissions by traffic and space heating are taken into account. The horizontal advection is neglected in the surface layer, and only the transport of pollutants by vertical diffusion is considered to take place. The next layer is the mixing layer, which extends to the inversion height. The height of this layer is constant during the night and grows during morning hours, and after sunset the nocturnal mixing height is established again. When the height of the mixing layer increases, this means that pollutants from the reservoir layer penetrate the mixing layer. The layer above the mixing layer is the reservoir layer. The top of this layer is determined by the effective height of the sources: Pollutants emitted above the mixing layer at night are injected in the reservoir layer. When the height of the mixing layer decreases, the reverse process takes place. This process is called fumigation. A vertically homogeneous concentration is assumed in this layer due to strong mixing. Exchange between the mixing layer and the reservoir layer only occurs by changes of the mixing height. The last layer is the upper layer. This layer serves as a semipermanent reservoir for pollutants released directly from the mixing layer during the afternoon, when the reservoir layer has vanished. The height of the upper layer is at least equal to the maximum possible mixing height. The concentrations in the surface layer are converted into concentrations at observation height, based on quadratic concentration profile. These last concentrations are directly compared with actual observations in the assimilation.

\subsection{Species and Chemistry}

[20] In the model, 15 species are taken into account: sulfur dioxide, sulfate, nitrogen oxide, nitrogen dioxide, ozone, hydroxyl radical, nitrate aerosol, ethane, butane, ethene, propene, xylene, isoprene, carbon monoxide, and nitric acid. Methane, also important for ozone formation, has been fixed in the model at $1700 \mathrm{ppb}$. The EUROS model contains all the relevant physical and chemical processes: emissions, advection, vertical exchange due to fumigation processes, horizontal and vertical diffusion, dry and wet deposition, and chemistry. The differential equations are solved using the operator splitting technique; this means that for each separate process, the concentration is solved during a time step of half an hour. The advantage of the operator splitting technique is that the most efficient numerical integration technique can be chosen for each process. Two chemical schemes are available within EUROS: a simplified 15-component scheme (17 reactions) and the Carbon Bond IV mechanism [Gery et al., 1989; van Loon, 1996; Hammingh et al., 2001] with 32 components and 86 reactions. The 15 -component scheme, based on the ideas of a model described by Stedman and Williams [1991], describes the essential characteristics of the life cycles and timescales involved in the formation of ozone in the boundary layer. Fumigation and wet deposition are incorporated as first-order processes and are explicitly solved in EUROS with a time step of half an hour. The differential equations describing vertical diffusion and dry deposition can be solved analytically, by assuming a quadratic profile for the concentration in the surface layer.
Horizontal diffusion is solved using a simple discretization second order in space. Advection is solved using a finite volume method (third-order scheme, upwind biased). Anthropogenic emissions are provided as yearly totals for different sectors (combustion, domestic, refinery, industry, solvents, traffic) and are specified as diffuse sources and point sources emission [Simpson et al., 1995]. A distribution function is used for each sector to distribute the emissions over the months, days of the week, and hours of the day.

\section{State Space Representation}

[21] In order to derive a state space representation of the EUROS model, a state vector, defined as the vector containing the ozone concentrations at each grid point of the model, is necessary. The EUROS model can now be rewritten as a state space model in the form:

$$
c^{t}\left(t_{k+1}\right)=M\left(c^{t}\left(t_{k}\right)\right)
$$

The stochastic extension of this is based both on a specification of the errors of the deterministic model EUROS and on the observations. Knowledge of the uncertainties in both the EUROS model and the observations is crucial for successful data assimilation. The description of the errors strongly affects the results of the assimilation. One of the goals of this study was to gain inside information in the uncertain parameters of the model and the impact of these parameters on the assimilation. One method to accomplish this is to treat these parameters as model input, and to define them as stochastic parameters. A disadvantage of modeling uncertainties using a white noise input, $w$, is that there is no memory in the system, i.e., $w$ is uncorrelated in time. At a certain time, $t$, the noise parameter may indicate an emission increase of 30\% with respect to the original field, whereas it estimates a decrease of $30 \%$ at $t+1$. Such irregular and unrealistic behavior can be prevented by the use of colored noise. The white noise input, $w$, forces a colored noise process, $\lambda$, which operates on the parameters in the model. The exact size of $\lambda$, depends on which parameter in the model is considered to be stochastic. Each element of $\lambda$ allows use of different values for the time correlation parameter, $\alpha=\exp (-1 / \tau)$, and the standard deviation $\sigma_{a}=\sigma \cdot \operatorname{sqrt}\left(1-\alpha^{2}\right)$. The parameter $\tau$ is the time correlation length in hours. Five parameters are considered uncertain. In the implementation of the Kalman filter with the EUROS model, the noise parameters form part of the model state [Segers, 2002], therefore making the use of an augmented state vector necessary. The general stochastical model (equation (2)) takes the following form:

$$
\left(\begin{array}{c}
c^{t}\left(t_{k+1}\right) \\
\lambda_{k+1}\left(t_{k+1}\right) \\
\lambda_{k}\left(t_{k+1}\right)
\end{array}\right)=\left(\begin{array}{c}
M\left(c^{t}\left(t_{k}\right), \lambda_{k}\left(t_{k}\right)\right) \\
\alpha \lambda_{k}\left(t_{k}\right) \\
\lambda_{k}\left(t_{k}\right)
\end{array}\right)+\left(\begin{array}{c}
0 \\
\sigma_{\alpha} I \\
0
\end{array}\right) w\left(t_{k}\right)
$$

or

$$
x^{t}\left(t_{k+1}\right)=M\left[x^{t}\left(t_{k}\right)\right]+G w\left(t_{k}\right)
$$


where the left-hand side of equation (20) is the state vector, $c$, the concentration array of all species in the model, and the matrix $G$ distributing the impact of the noise values for all the parameters considered uncertain in the model in specific areas.

\subsection{Uncertain Model Parameters}

[22] The two types of model errors identified are for model input and modeling. The model input errors are due to errors in emissions, meteorological fields and boundary conditions. Modeling errors result from the parameterization of the processes in the model, e.g., chemistry, transport, and deposition.

[23] In atmospheric models, emissions form an important input parameter, but are usually somewhat uncertain. The emissions of $\mathrm{NO}_{\mathrm{x}}$ and VOCs are taken here to be uncertain parameters and put in a stochastic environment using

$$
e_{s}\left(t_{k}\right)=\bar{e}_{s}^{j}\left(t_{k}\right)\left[1+\lambda_{s}\left(t_{k}\right)\right], s=\left\{N O_{x}, V O C\right\},
$$

where $\bar{e}_{S}$ is the deterministic value of the $\mathrm{NO}_{\mathrm{x}}$ and VOC emissions in a grid cell. The distribution function used to distribute the emissions over the months, days of the week, and hours of the day is now applied to $e_{s}\left(t_{k}\right)$.

[24] Because of the complex chemistry of the EUROS model, errors in the chemical parameters will affect the computed concentrations. One of these parameters is the value of the photolysis rates. From a study of Thompson and Stewart [1991] on the impact of chemical kinetics on uncertainties in tropospheric models, we deduced that the primary photodissociation reactions

$$
\begin{gathered}
\mathrm{NO}_{2}+h \nu \rightarrow \mathrm{NO}+\mathrm{O} \\
\mathrm{O}_{3}+h \nu \rightarrow \mathrm{O}_{2}+\mathrm{O}\left({ }^{1} \mathrm{D}\right)
\end{gathered}
$$

have a large direct impact on the formation and destruction of ozone in the troposphere. In the 15-component chemistry scheme these reactions are not used explicitly, but combined with other reactions to produce ozone. The concentrations of all other species are correlated with the elements from these reactions. They also have a great impact on the ozone concentrations, since they lead to the formation and destruction of ozone. The uncertainties in the photolysis rates is modeled according to

$$
J_{s}\left(t_{k}\right)=\bar{J}_{s}\left(t_{k}\right)\left[1+\lambda_{s}\left(t_{k}\right)\right], s=\left\{N O_{2}, O_{3}\right\},
$$

where $\bar{J}_{s}\left(t_{k}\right)$ denotes the deterministic value. Because of the implementation of the chemistry in our model, uncertainties in photolysis rates also include uncertainties in cloud cover and radiation in the atmosphere.

[25] Another important parameter is the deposition rate. The deposition rate of ozone is a source of uncertainties for assimilation of ozone measurements. The deposition rates are modeled according to

$$
R_{O_{3}}\left(t_{k}\right)=\bar{R}_{O_{3}}^{j}\left(t_{k}\right)\left[1+\lambda_{O_{3}}^{*}\left(t_{k}\right)\right]
$$

where $\bar{R}_{O_{3}}$ denotes the deterministic value.

[26] Four different regions for the emissions of $\mathrm{NO}_{\mathrm{x}}$ and VOCs, and for the deposition rate of ozone, are defined for the noise parameters. This is shown in the equations by attaching the superscript, $j$, to the deterministic values. The four different regions are (1) the Netherlands, Belgium, and Luxembourg, (2) Germany and Denmark, (3) France, and (4) the United Kingdom and Ireland. These four regions are used to provide a better explanation of the noise parameters and to obtain improved emissions for these four regions. For all noise parameters, values have been confined to between 0.2 and 5 (multiplication factors), so as to prevent unrealistic variations in the model input and instabilities in the model simulations.

[27] The uncertainties caused by the limitations of the model are represented in the state space approach by the $w$ noise process. Because the noise parameters described above are embedded in the state vector, they will be propagated through the model and analyzed by the mean and covariance. These uncertainties can therefore be reduced to obtain the optimal estimate of the concentrations and noise parameters and give information about the true state of the atmosphere and the noise parameters. The noise parameters defined above can be interpreted as correction factors to the emissions, photolysis rates, and deposition rate. The values of the noise parameters depend on the model and, in theory, they only represent the true state if the model is perfect. In practice a model is, of course, never perfect, but the chemistry-transport model EUROS has been validated extensively (and continuously) with measurements before being used in this assimilation. Nevertheless, considerable attention should be paid to the interpretation of these correction factors. They are only "optimal" within the constraints of the EUROS model.

\subsection{Ground-Based Observations}

[28] To improve the estimation of the assimilated concentrations of ozone and to reduce the uncertainties in the emissions, the model is combined with available measurements. Time series of measurements at surface level were obtained from the Netherlands Air quality Monitoring Network, LML [Elzakker, 2001], from the EMEP (A. G. Hjellbrekke, Ozone measurements 1996, EMEP/CCC 3/98, 1998, available from the EMEP Web site at http://www. emep.int/) and Airbase (ETC-ACC, Airbase from the European Topic Centre on Air Quality and Climate Change, 2003, available at http://air-climate.eionet.eu.int/databases/ airbase.html) databases. Airbase, a Web-based database of information and data on air quality across Europe, is managed by the European Topic Centre on Air Quality and Climate Change of the European Environment Agency. Only ozone observations at background stations are used in the assimilation, since the output of the EUROS model represents the ozone concentrations on the same scale. Therefore, if observations are to be taken into account, they must be measured at stations marked as "background" and "rural" and located at an elevation not higher than $500 \mathrm{~m}$ above sea level. For the period studied (summer 1996) data was available for in total 135 of those stations in Europe. This set of 135 stations was split in three sets. Two sets (set 1 and 2), each with 56 stations, were constructed in such a way that the stations have about the same spatial distribution in set 1 and set 2 . There is one station per grid cell for the sets 1 and 2. One of these sets is used for assimilation (assimilation stations) while the other is used for diagnostic 


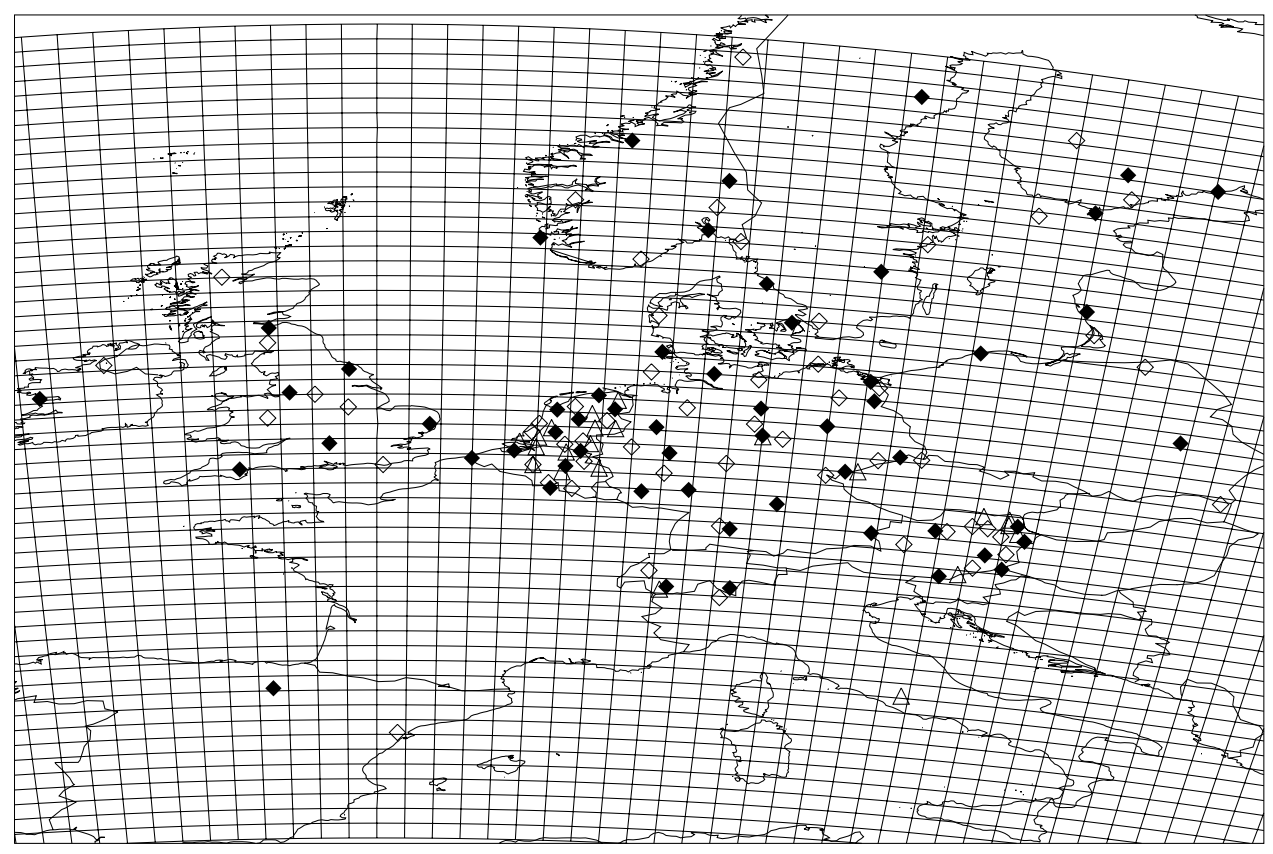

Figure 1. Stations with ozone observations in Europe in June 1996. Stations used (default) for assimilation (set 1) are marked by solid diamonds, and the stations used (default) for validation are marked by open diamonds (set 2) and open triangles (set 3). Part of the EUROS grid is shown as well. If there is more than one station per grid cell, only one is used for the assimilation; the other is indicated by an open triangle. For the year 1996 there is only one observation in France in the databases.

purposes (validation stations). The remaining 23 stations are mostly located in grid cells that already contain a station from one of the two other sets. This third set of stations is only used for diagnostics. The stations of these three sets were chosen such that they are evenly distributed over Europe (Figure 1).

[29] The model state was compared with the observations $y^{o}\left(t_{k}\right)$ in accordance with equation (4). The observation operator $H\left(t_{k}\right)$ assigns the ozone level in the surface layer of a grid cell to an observation and $v\left(t_{k}\right)$ is the representativeness error plus the measurements error.

[30] For each ozone measurements it is assumed that the standard deviation of the error is equal to $10 \mu \mathrm{g} \mathrm{m}^{-3}$. This error accounts for both the uncertainty in the actual concentration measured at the specific station as well as for a representation error, reflecting the size of the grid cell. This uncertainty is in agreement with the estimation of the observation error variance of $10 \mathrm{\mu g} \mathrm{m}^{-3}$ found by Flemming et al. [2003]. His result is based on an observational method [Hollingsworth and Lönnberg, 1986]; that is, the observation error variance for a certain station is obtained by extrapolating of the covariance field from surrounding stations by means of a spherical covariance model.

\section{Results and Discussion}

[31] A whole set of simulations has been performed to study to what extent the information can be improved by using the combination of the EUROS model and the Kalman filter. The assimilation results depend on the model and on the parameters involved in the process, e.g., the number of observations, the accuracy of the algorithms, and the noise specification. In this section several aspects of the assimilation are discussed to gain insight in the behavior of the Kalman filter in combination with the EUROS model and the ozone observations. The validation and general results of assimilation are discussed first, followed by a description of the performance of the two algorithms (RRSQRT and ENKF), convergence with the number of modes and the effects of the randomness in the ENKF algorithm. This is followed by a discussion on the effects of the number and location of the observations used in the assimilation. In the last sections the effects of the specification of the noise parameters (type, size, and location) on the assimilation are discussed.

[32] A number of different model parameters have been considered to be uncertain and defined as stochastic parameters in the simulations. For the default case, the model uncertainty is specified in terms of uncertain emissions for $\mathrm{NO}_{\mathrm{x}}$ and VOCs, uncertain photolysis rates for $\mathrm{NO}_{2}$ and $\mathrm{O}_{3}$, and an uncertain deposition rate for $\mathrm{O}_{3}$. The standard deviation of $w$ in equation (20) was set to $30 \%$ and the time correlation parameter to 24 hours for emissions of $\mathrm{NO}_{\mathrm{x}}$. For emissions of VOCs, which are believed to be more uncertain, the standard deviation was increased to $50 \%$ with the same time correlation parameter. Both of the $\mathrm{NO}_{2}$ and $\mathrm{O}_{3}$ photolysis rates for the standard deviation were set to $50 \%$ and the time correlation parameter to 6 hours. Finally, for the deposition rate of $\mathrm{O}_{3}$ the standard deviation was set to $30 \%$ and the time correlation parameter to 24 hours. The noise parameters were applied for all four regions for the emissions of $\mathrm{NO}_{\mathrm{x}}$ and VOCs and for the deposition of $\mathrm{O}_{3}$ (see section 4.1).

[33] Most simulations discussed in this section cover the period 1-30 June 1996, but for a number of simulations (in the sections 5.3, 5.4, and 5.6) the period is limited to 
1-7 June 1996 to reduce the computation time. Simulations covering periods of one, two, three, or four weeks yield the same results from the point of view of the improvement of the assimilated concentrations.

[34] To quantify the effect of the various simulations, we calculated the residual between the simulated and the measured ozone concentrations. For a single point in time, the residual is defined as the difference between the measurement and the simulated concentration, if a measurement was available. For the whole time series the term absolute average residual (AAR) is introduced, defined as

$$
A A R=\frac{1}{N} \sum_{i=1}^{N}\left|c_{i}^{\text {observed }}-c_{i}^{\text {simulated }}\right|,
$$

where $N$ is the number of valid measurements in the time series and the simulated concentration can refer to the EUROS model alone or the KF results. Similar results are obtained if the root mean square error instead of the absolute average residuals is used for the analysis. The same term (AAR) was used in a previous research for smog forecast with a chemistry model using data assimilation [Velders et al., 2001].

\subsection{Validation}

[35] A way to validate the method is a twin experiment using simulated data. This method was performed to test the data assimilation performance for small-scale atmospheric transport models in studies by Segers [2002] and Velders et al. [2001]. Measurements are drawn from simulations with the model. In this research, after the assimilation was performed, a validation of the results of filter experiments should be done. An objective way of validation in this case is to split in two the available measurement sites. The data from the first set of measurements will be used in the assimilation process and the Kalman filter will take it into account in the measurement update step. These stations are called assimilation stations. The data from the other half is not used in the assimilation process. The information from the first set is used by the Kalman filter to obtain the optimal estimate for the state, and the other set is not used in the assimilation process but only to verify the results. These stations are called validation stations.

[36] The ozone observations (see Figure 1) of set 1 are used by default for assimilation while the stations of set 2 and 3 are used only for validation, unless indicated otherwise. Similar results are obtained when set 2 is used for assimilation and set 1 for validation, because of the large number of observations in each set.

\subsection{Setup of Assimilation}

[37] The general behavior of a data assimilation simulation is explained and discussed using a simulation with the ENKF algorithm with 20 modes for 1-30 June 1996. First, the ozone time series at two stations in the Netherlands are shown followed by the time-averaged behavior of all validation station stations in the Netherlands, and the performance of the assimilation for the whole of Europe. The focus in the experiments is on the improvement of the accuracy of the simulated ozone concentrations (smaller residuals) using the Kalman filter. a) Biddinghuizen - no assimilation

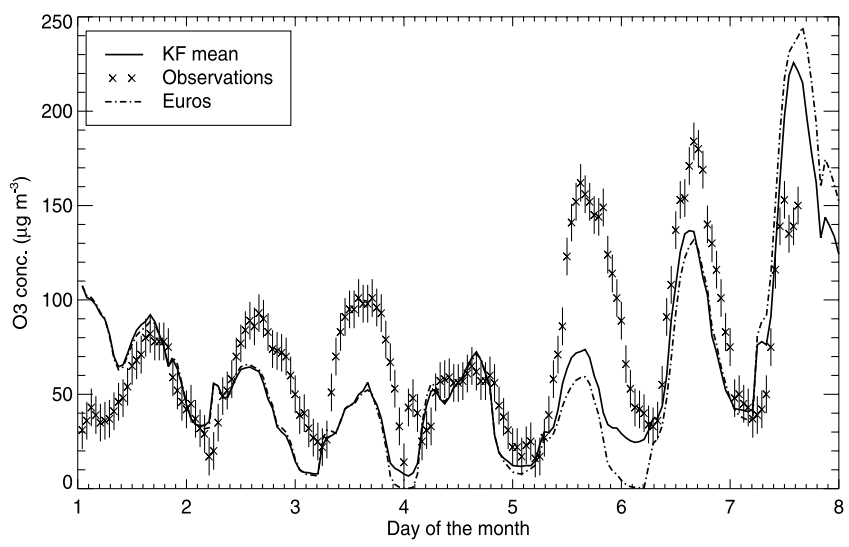

b) Biddinghuizen - assimilation station

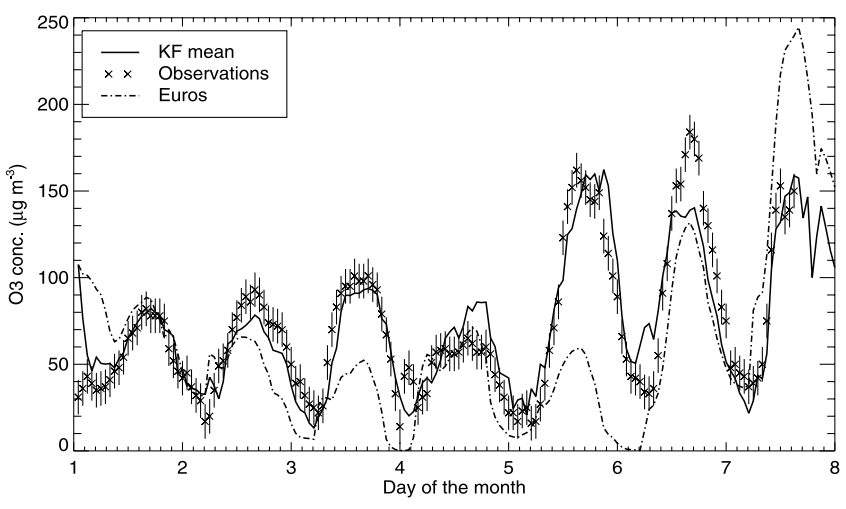

c) Hellendoorn - validation station

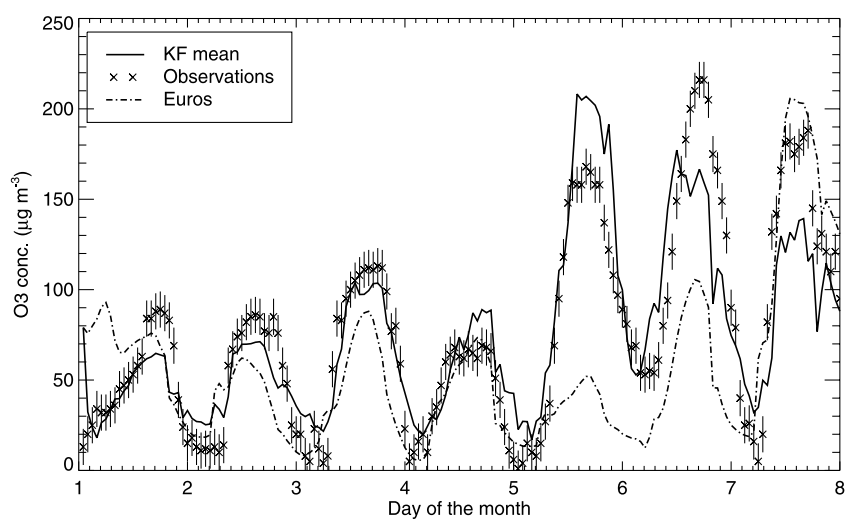

Figure 2. Ozone concentrations $\left(\mu \mathrm{g} \mathrm{m} \mathrm{m}^{-3}\right)$ at station Biddinghuizen (Netherlands) (a) without and (b) with data assimilation for the Kalman filter mean (solid lines) for 17 June 1996, calculated with ENKF with 20 modes. (c) Ozone concentrations at validation station Hellendoorn (Netherlands), of which the observations are not used in the assimilation process. Data from the EUROS model (dashdotted lines) and the observations (crosses) are also shown. The vertical bar of the crosses represents the uncertainty in the observations given as input in the assimilation.

[38] Figure 2 show the Kalman filter mean (KF mean) ozone concentration without (Figure 2a) and with (Figure 2b) assimilation. Also shown are the ozone concentrations from the EUROS model and from the observations. Without 


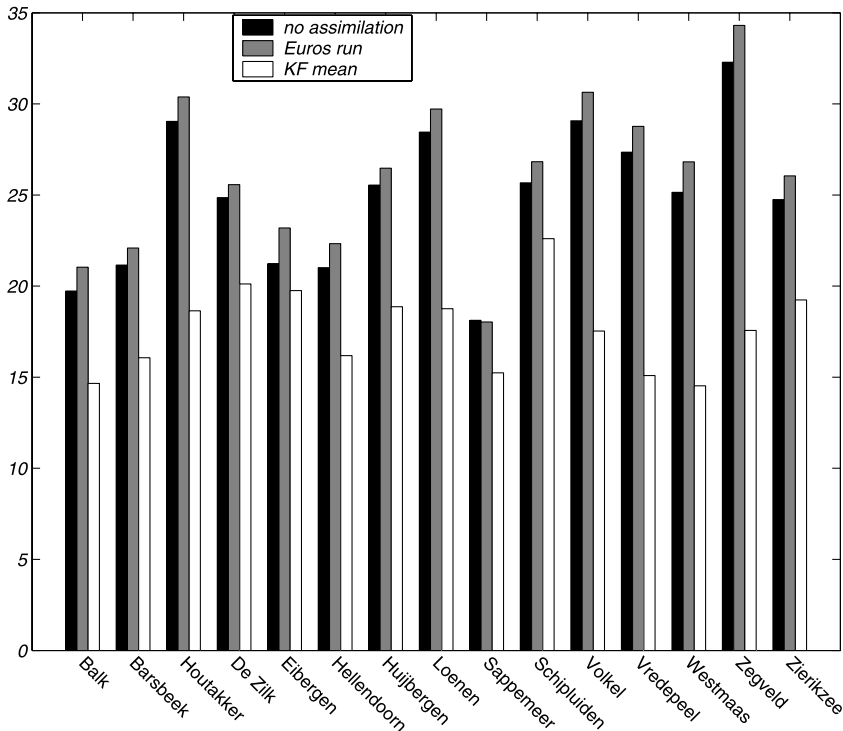

Figure 3. AARs $\left(\mu \mathrm{g} \mathrm{m}^{-3}\right)$ of an assimilation (ENKF, 20 modes) for all the validation stations in the Netherlands for the EUROS model calculation, the KF mean, and the mean without assimilation. Simulation for June 1996.

data assimilation (Figure 2a), no observations are used in the simulation and the KF mean is simply the statistical mean of the 20 separate model calculations. The improvement in ozone concentration is clear in the case where observations are assimilated. The assimilated time series for this station are in better agreement with the observations than the ones calculated by the model alone. This improvement cannot only be observed at measurement sites the observations of which are used in the assimilation procedure (i.e., so-called assimilation stations); it also holds for validation stations the observations of which are not used in the assimilation. In Figure $2 \mathrm{c}$ the concentration for the validation station Hellendoorn is shown. A similar improvement of the concentration given by the Kalman filter mean in the direction of the measurements is shown. The data from this station is not used in the assimilation process. This proves that more accurate concentrations are obtained not only for assimilation stations, but also for validation stations.

[39] In Figure 3 the absolute average residuals (AARs), averaged over a month, are shown for all the validation stations in the Netherlands. The first bar represents a run without assimilation, the second bar the EUROS run, and the last one the KF mean. The difference between the first two bars is due to the stochastic noise that was implemented in the model and the slightly better performance of the first is a consequence of the averaging. In all the stations the improvement given by the KF mean is evident.

[40] A comparison between the AARs based on the EUROS model and those based on the KF mean at all measurement sites over a part of Europe is presented in Figure 4. The Kalman filter improves the ozone concentrations at 85 of the 124 stations with data in Europe by an averaged $32 \%$, while for 27 of the 124 stations with data there is no significant improvement (change between $-10 \%$ and $10 \%)$. For 12 stations the AAR of the KF mean is larger than the AAR of EUROS (change $>10 \%$ ). Nearly all of these stations are located in Scandinavia, i.e., outside the regions with noise in the emissions of $\mathrm{NO}_{\mathrm{x}}$, VOCs and in the deposition of ozone. Figures $2-4$ show that when data assimilation is applied, in general the residuals decrease both at the assimilation and the validation stations, indicat-

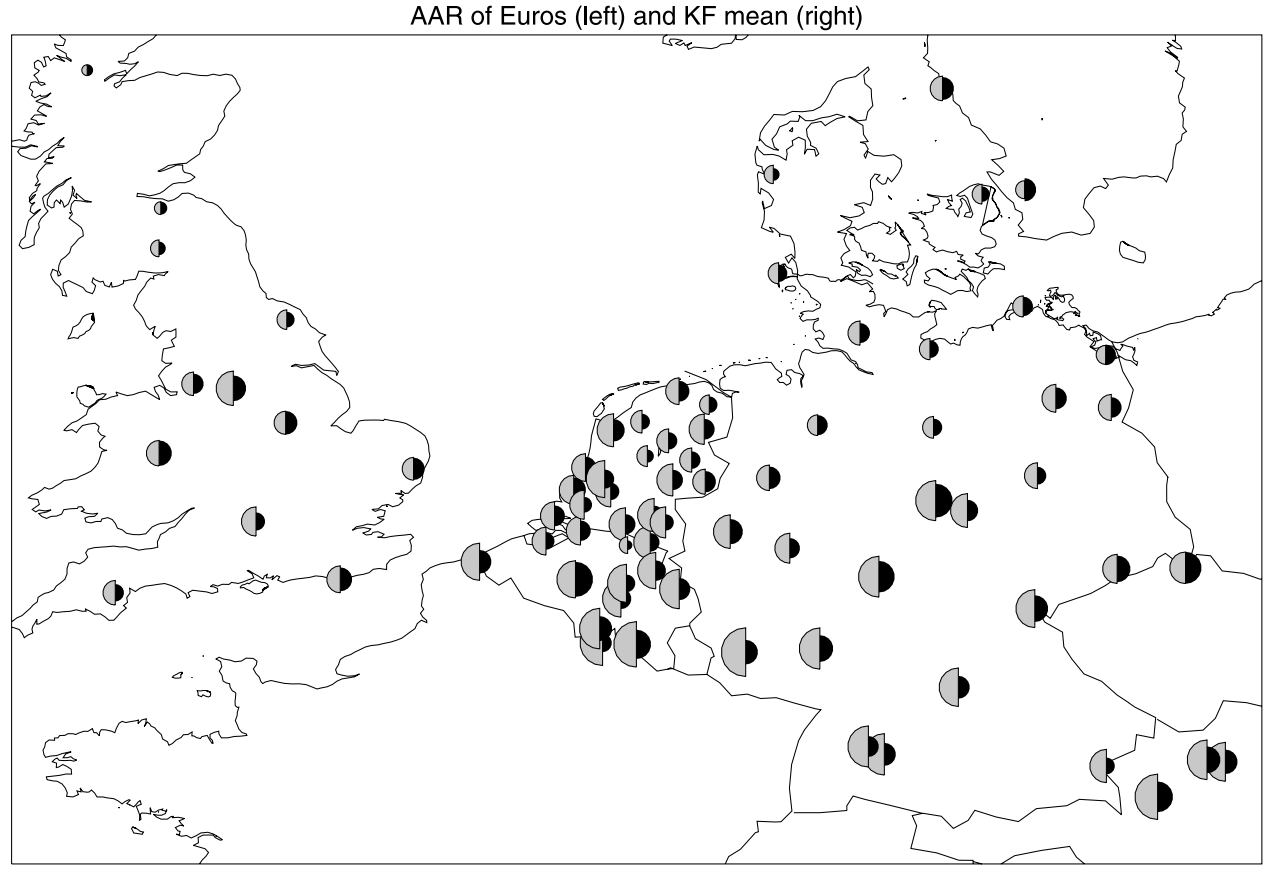

Figure 4. AARs $\left(\mu \mathrm{g} \mathrm{m}^{-3}\right)$ based on the concentrations from the EUROS model (left half circles) and the KF mean (right half circles) for a data assimilation simulation using the ENKF algorithm with 20 modes. The period of the assimilation was June 1996. 
ing proper functioning of the data assimilation. Similar results were obtained with an alternative set of measurement sites (set 2) for the assimilation, because each set contained a large number of sites and because the regions to which noise is applied are much larger than the distance between the measurement sites.

[41] Since an improvement at the assimilated stations is expected anyway, in most simulations the analysis was based on the data for the validation stations. Table 1 shows AARs for the validation and assimilation stations in the Netherlands, the regions with noise in the emissions, and the whole of Europe for the diurnal average, the daytime average, and the nighttime average. It can be seen that, on average, the residuals decrease by $30-39 \%$ for the stations in the Netherlands, by $23-35 \%$ for the stations in the noise regions, and by $20-29 \%$ for all stations in Europe. The decrease in the average residuals in the Netherlands is larger than that for Europe as a whole probably because of the large density of stations in the Netherlands. The results for only the stations in the regions with noise in the emissions are somewhat better than those for Europe as a whole, indicating that outside the regions with the main noise factors (see section 5.6) the Kalman filter cannot improve the EUROS model as much as for the regions with noise. The improvement in AARs is somewhat larger for the daytime values than for the nighttime values. There is almost no difference between the validation and assimilation stations, because of the relatively small distance between the stations (both for validation and assimilation) compared with the size of the noise regions. The assimilation improves the concentrations at both the assimilation and validation stations with about the same magnitude. Because oft the large size of the noise regions the information from the observations is averaged over various stations. As a result there is an inherent lower limit for the AAR values. This lower limit depends on the spatial variability in the EUROS output, but also on the variability between neighboring stations. If only one stations is used in an assimilation (see section 5.4 and Table 3 ) the AAR of this assimilation station drops from $19.4 \mu \mathrm{g} \mathrm{m}^{-3}$ for the EUROS model to $7.3 \mu \mathrm{g} \mathrm{m}^{-3}$ for the KF mean. By assimilating the data of only one station, the Kalman filter can obtain a better result for this single station. Alternatively, by using only regions with noise, one can reduce the averaging effect and make sure that the Kalman filter yields results that are in close agreement with the observations and consequently in a lower AAR. The simulations discussed here cover a period of one week or one month. Close investigation of the result shows that similar improvements in the assimilated concentrations are obtained when periods of one, two, three, or four weeks or even longer are simulated. Both the EUROS model and the Kalman filter require a startup period, since to initial conditions from the EUROS model and from the Kalman filter algorithms lack information at the beginning of the simulations. This startup period is short, about a day, and has a small effect on the absolute values of the AAR, but it hardly affects the improvement in the AAR data from the assimilation.

[42] The same effects as those discussed above are obtained if the root mean square error is calculated instead of the absolute average residual. The absolute values are different but the relative improvements obtained by the
Table 1. AARs Averaged Over All Validation and All Assimilation Stations in the Netherlands, in the Regions With Noise and in Europe for the Diurnal, Daytime, and Nighttime Averages Calculated With the ENKF Algorithm With 20 Modes for 130 June $1996^{\mathrm{a}}$

\begin{tabular}{|c|c|c|c|c|c|c|}
\hline \multirow[b]{2}{*}{ Stations } & \multicolumn{2}{|c|}{ Diurnal } & \multicolumn{2}{|c|}{ Daytime $^{b}$} & \multicolumn{2}{|c|}{ Nighttime $^{\mathrm{b}}$} \\
\hline & EUROS & $\begin{array}{c}\text { KF } \\
\text { Mean }\end{array}$ & EUROS & $\begin{array}{c}\text { KF } \\
\text { Mean }\end{array}$ & EUROS & $\begin{array}{c}\text { KF } \\
\text { Mean }\end{array}$ \\
\hline NL validation & 26.1 & 17.7 & 26.7 & 17.4 & 25.6 & 17.9 \\
\hline NL assimilation & 26.8 & 17.2 & 24.9 & 15.1 & 28.7 & 19.1 \\
\hline Regions validation & 26.6 & 19.3 & 27.2 & 18.6 & 26.2 & 20.3 \\
\hline Regions assimilation & 26.6 & 18.3 & 26.0 & 16.8 & 27.3 & 19.7 \\
\hline Europe validation & 27.7 & 20.8 & 27.9 & 19.8 & 27.6 & 22.0 \\
\hline Europe assimilation & 27.0 & 20.0 & 26.5 & 18.8 & 27.5 & 21.3 \\
\hline
\end{tabular}

${ }^{\mathrm{a}} \mathrm{AAR}$ values are given in $\mu \mathrm{g} \mathrm{m}^{-3}$. Regions are defined here as the total area covering the regions Netherlands-Belgium-Luxembourg, France, Germany-Denmark, and the UK-Ireland, i.e., the regions with noise in emissions of $\mathrm{NO}_{\mathrm{x}}$ and VOCs and noise in the deposition of $\mathrm{O}_{3}$.

${ }^{\mathrm{b}}$ Daytime is defined as 0800 to $2000 \mathrm{UT}$, and nighttime is defined as 2000 to 0800 UT.

assimilation compared by those obtained only with EUROS calculation are in very close agreement.

\subsection{RRSQRT Versus ENKF and Number of Modes}

[43] A parameter that is important for the assimilation in both algorithms is the number of modes used in assimilation. Simulations with different numbers of modes were performed in order to study the sensitivity of the model to this parameter and to try to find an optimum number which gives good estimates, but at the same time requires a computation time that is not too long. The accuracy of the assimilation is expected to increase with the number of modes, but the computation time also increases, about linearly, with the number of modes. The assimilated time series of the ozone concentration with the ENKF algorithm for $3,5,10,20,50$, and 80 modes were compared with similar calculations for the RRSQRT algorithm and with the time series given by the EUROS model over the whole domain. The AAR values are presented in Figure 5. The behavior of the algorithms with a real-life large-scale model is consistent with the specific theoretical characteristics of these algorithms discussed in Section 2, like the robustness of RRSQRT filter in comparison with the ENKF for a small number of modes and the convergence of both algorithms when the ensemble size (number of modes for RRSQRT) are increasing. The same performance of the two algorithms can also be seen in Figure 6. The AARs are plotted versus the number of modes for both algorithms. Presented are the AARs after the simulations with the ENKF and the RRSQRT algorithms with different kinds of noise parameters. It shows that the use of all the noise parameters simultaneously gives the smallest values for the AARs: less than $25 \mu \mathrm{g} \mathrm{m}^{-3}$. The AARs obtained when only one noise parameter is taken into account are in general about $30 \mu \mathrm{g} \mathrm{m}^{-3}$. The results show that for noise in the photolysis of ozone, higher values are obtained $\left(32-33 \mu \mathrm{g} \mathrm{m}^{-3}\right)$, and lower ones for noise in emissions of $\mathrm{NO}_{\mathrm{x}}\left(28-29 \mu \mathrm{g} \mathrm{m}^{-3}\right)$ and VOCs $\left(30 \mu \mathrm{g} \mathrm{m}^{-3}\right)$. In most panels of Figure 6 the AARs of the RRSQRT algorithm decrease faster with increasing number of modes than with the ENKF algorithm, but both attain about the same end values. This difference in the behavior is mainly caused by the different way of 


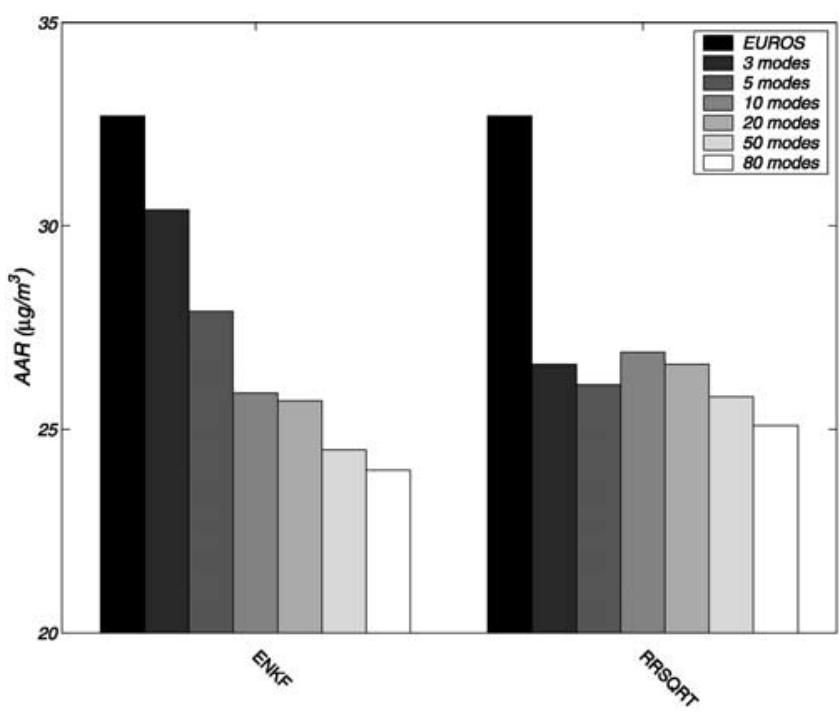

Figure 5. Comparison of the performance of the ENKF algorithm and the RRSQRT algorithms using different numbers of modes/ensembles. The AARs $\left(\mu \mathrm{g} \mathrm{m}^{-3}\right)$ are averaged over all the validation stations in Europe. Noise was applied to all five parameters.

handling nonlinearity in the RRSQRT and ENKF algorithms. After achieving a large reduction in AARs with only a small number of modes, the RRSQRT algorithm starts to become unstable and the use of more modes only results in a small improvement in AARs. This instability is shown in Figure 5, where the RRSQRT algorithm has higher AAR values for 10 modes than for 3 and 5 modes. The instability is caused by the numerical problems en- countered in the eigenvalue decomposition (equation (16)) [see, e.g., Canizares, 1999]. Because of its statistical properties, the ENKF algorithm can handle the nonlinearity of the model much better, but it requires a large number of modes (i.e., ensembles).

[44] The number of modes can also be translated into computational time in the following way. When the RRSQRT algorithm is applied, for example, with 20 modes, the Kalman filter uses 20 modes plus the noise parameters for that specific simulation (see equation (18)). This results in different computation times for a RRSQRT simulation with 20 modes than for an ENKF simulation with 20 modes. If we compare the improvements in concentrations given by the $\mathrm{KF}$ algorithms and the required computation times, it seems that 10-20 modes is sufficient for both algorithms. The computation time increases linearly with more modes, while the improvement obtained is small.

\subsection{Randomness in ENKF}

[45] To test the effect of the randomness, nine ENKF simulations were performed, each with $3,5,10,20,50$, and 80 modes respectively. In the nine simulations different random numbers were used each time. The first (black) bar in Figure 7 for each number of modes represents the EUROS run, followed by nine different simulations with the same number of modes but with different random numbers. One can observe that the randomness has an influence only in cases where the ensemble size is small (see cases for 3, 5, and 10 modes). When the number of modes increases, a convergence of the AAR values is obtained, and the influence of randomness in assimilation is negligible. Anderson [2001] also showed that an ensemble Kalman filter with a limited number of ensembles and perturbed observations could lead to imperfections in the
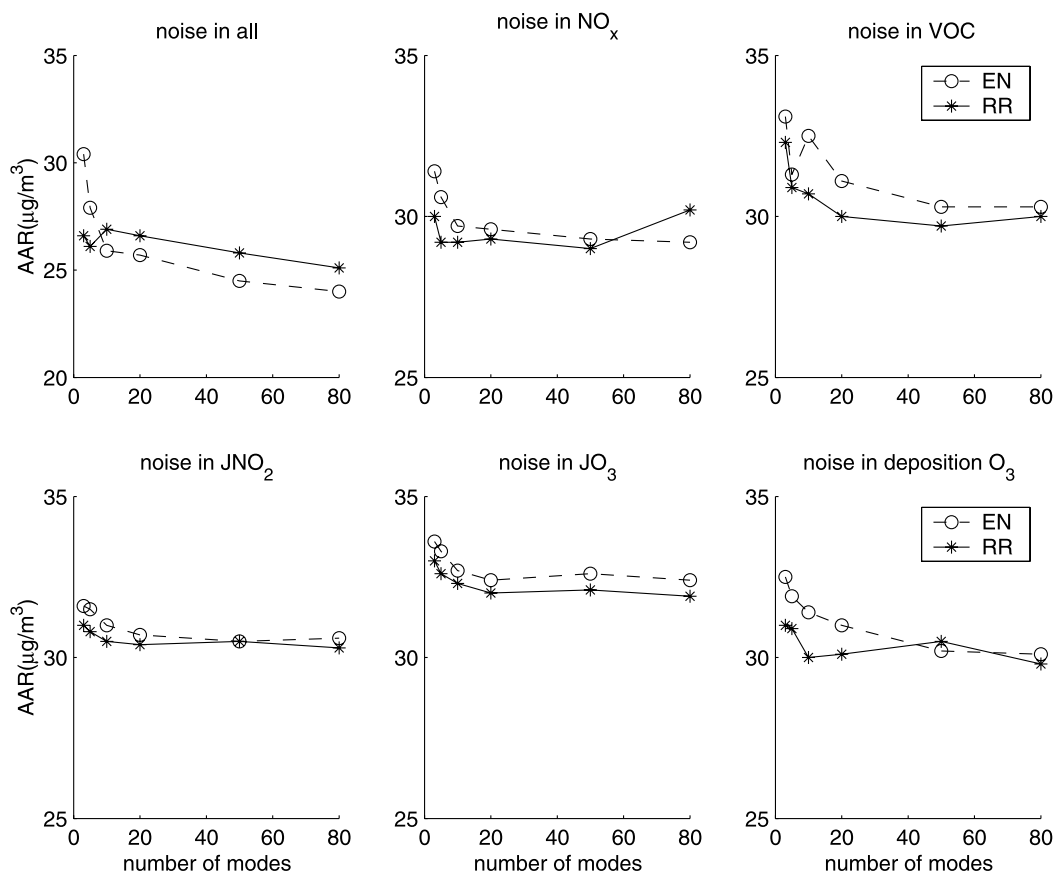

Figure 6. Comparison of the performance of the ENKF and RRSQRT algorithms using different numbers of modes/ensembles. The AARs $\left(\mu \mathrm{g} \mathrm{m}^{-3}\right)$ are averaged over all the validation stations in Europe. 


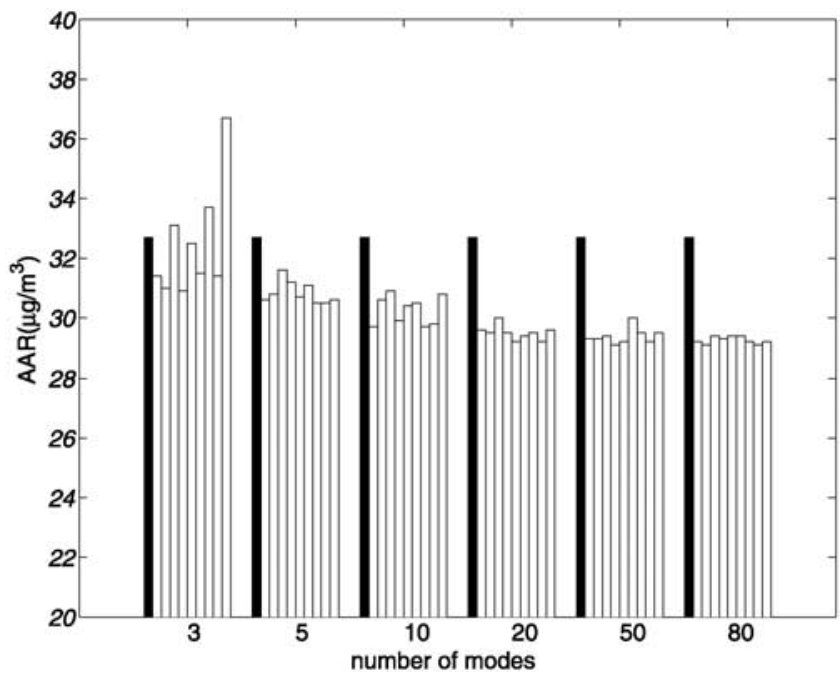

Figure 7. Influence of the randomness on the AARs $\left(\mu \mathrm{g} \mathrm{m}^{-3}\right)$ of the ENKF algorithm. The first bar represents the AARs obtained from an EUROS simulation. The nine bars that follow, for each different number of modes, are the AARs of nine Kalman filter simulations, each with different random numbers. Noise was applied only to the $\mathrm{NO}_{\mathrm{x}}$ emissions (in four regions).

assimilation. In Table 2 the results of the same simulations are shown together with the average, the standard deviation of the average, and the average of the square root of the covariance matrix ( $p$ in equation (9)). The variation (standard deviation) in AARs for 20 modes or more is much smaller than the square root $(p)$. So using more modes with the ENKF algorithm is not useful since the intrinsic uncertainty of the assimilation, derived from the covariance, becomes a limiting factor. The growth of the variance (= averaged square root $(p)$ ) with increasing number of ensembles (modes), presented in the last row of Table 2, is caused by the fact that the use of a small number of ensembles in the ENKF algorithm leads to a loss in variance. On the other hand introducing more ensembles the variance will increase and will have effect on the averaged sqrt $(p)$. It also can be observed that the averaged sqrt $(p)$ is always much smaller that the averaged AAR values. This will be explained in section 5.5. In the simulations discussed here there was only noise in the $\mathrm{NO}_{\mathrm{x}}$ emissions in four regions. If more regions or more noise parameters are used, however, more than 10-20 modes might be required.

\subsection{Effect of Observations}

[46] The predicted values of concentrations in the data assimilation can be improved when an observation becomes available, i.e., in the measurement update step (equation (9)). Therefore the set of observations used in the assimilation are important for the accuracy of the assimilated concentrations. One can ask what impact of observations in a foreign site (i.e., non-Dutch site) has on the performance of the assimilation in the Netherlands? To answer this question, a number of simulations were performed using different sets of observations and investigating the performance of the assimilated concentrations in different regions: all stations in Europe or
Table 2. Influence of the Randomness on the AARs of the ENKF Algorithm With Different Numbers of Modes for 1-7 June $1996^{\text {a }}$

\begin{tabular}{lcccccc}
\hline & 3 & 5 & 10 & 20 & 50 & 80 \\
& Modes & Modes & Modes & Modes & Modes & Modes \\
\hline EUROS & 32.7 & 32.7 & 32.7 & 32.7 & 32.7 & 32.7 \\
Average & 32.5 & 30.9 & 30.2 & 29.5 & 29.4 & 29.3 \\
S.d. average & 1.88 & 0.38 & 0.49 & 0.24 & 0.27 & 0.13 \\
Average sqrt $(p)$ & 0.43 & 0.58 & 0.71 & 0.89 & 0.96 & 0.99 \\
\hline
\end{tabular}

${ }^{\mathrm{a}} \mathrm{AAR}$ values are given in $\mu \mathrm{g} \mathrm{m}^{-3}$. The average and standard deviation (s.d.) are from nine simulations with different random numbers. Also shown are the square root (sqrt) of the diagonal of the covariance matrix $\left(P^{a}\right.$ in equation (9)) AARs $\left(\mu \mathrm{g} \mathrm{m}^{-3}\right)$ averaged over all validation stations in Europe. Noise was applied only to the $\mathrm{NO}_{\mathrm{x}}$ emissions (in four regions).

only those from the Netherlands, and all stations outside of the Netherlands (called the foreign stations).

[47] Table 3 presents the results of ENKF simulations with different sets of assimilation stations. The difference between the AARs obtained using the stations of set 1 or set 2 is only $0.1 \mu \mathrm{g} \mathrm{m}^{-3}$. The reason the AARs are hardly affected by the choice of observations is that there are many observations in each set and only a small number of noise parameters (regions) in the assimilation, resulting in an averaging of the information in the observations. Only slightly small AAR values are obtained using all the assimilated stations, i.e., set $1+$ set 2 . Using only one or seven stations in the Netherlands in the assimilation yields a considerable reduction in AARs for the stations in the Netherlands, but hardly effects the stations outside the Netherlands. The lowest AAR values are obtained for the Netherlands using all seven stations in the Netherlands in the assimilation. The AARs for the foreign stations are, in this case, larger than in the other simulations. Using the 49 foreign stations (i.e., not in the Netherlands) in the assimilation results in a reduction in AARs, for the Netherlands of $4.9 \mu \mathrm{g} \mathrm{m}^{-3}$, compared with the AARs of the EUROS model. This is almost half decrease using all 56 stations of set 1. Furthermore, the same AAR values are obtained for the Netherlands in the case of assimilation

Table 3. Effect of the Number of Observations on the AARs and Average Standard Deviations Averaged Over All the Stations (of Sets 1, 2, and 3) From Three Regions: Netherlands, Foreign Stations (Europe Minus the Netherlands), and All Stations in Europe $^{\mathrm{a}}$

\begin{tabular}{|c|c|c|c|c|c|c|}
\hline \multirow[b]{2}{*}{ Assimilation Stations } & \multicolumn{3}{|c|}{$\mathrm{AAR}, \mu \mathrm{g} \mathrm{m}^{-3}$} & \multicolumn{3}{|c|}{$\begin{array}{c}\text { Standard } \\
\text { Deviation, } \mu \mathrm{g} \mathrm{m}^{-3}\end{array}$} \\
\hline & NL & Foreign & All & NL & Foreign & All \\
\hline EUROS & 26.4 & 27.6 & 27.4 & & & \\
\hline No assimilation & 25.1 & 26.0 & 25.8 & 19.2 & 13.8 & 14.8 \\
\hline Set 1: 56 stations & 17.5 & 21.2 & 20.5 & 2.2 & 1.3 & 1.5 \\
\hline Set 2: 56 stations & 17.4 & 21.1 & 20.4 & 2.3 & 1.5 & 1.6 \\
\hline Seven NL stations of set 1 & 14.7 & 29.0 & 26.4 & 3.6 & 4.6 & 4.4 \\
\hline One NL station of set 1 & 22.1 & 27.1 & 26.2 & 8.4 & 10.1 & 9.8 \\
\hline Foreign stations (49) of set 1 & 21.5 & 21.2 & 21.2 & 3.8 & 1.5 & 1.9 \\
\hline Sets 1 and 2: 112 stations & 15.9 & 21.4 & 20.4 & 1.8 & 0.9 & 1.1 \\
\hline
\end{tabular}

${ }^{\mathrm{a}} \mathrm{AAR}$ values are given in $\mu \mathrm{g} \mathrm{m}^{-3}$. Standard deviation equals sqrt $(p)$ in $\mu \mathrm{g} \mathrm{m}{ }^{-3}$. NL, Netherlands. ENKF simulation with 20 modes for $1-30$ June 1996. The assimilation stations used are as follows: sets 1 and 2, all stations in the Netherlands, one station in the Netherlands (Biddinghuizen), all nonDutch stations, and the combined sets 1 and 2. Also shown are the results of the EUROS model and those of a simulation without assimilating any stations (first two rows). 
with 49 foreign stations and the case of assimilation with only one station in the Netherlands. These results clearly show that the observations have their largest impact locally and very small impacts further away. Furthermore, using observations from stations in the Netherlands only limited information can be obtained for regions more than a few hundred kilometers away.

[48] If one looks at the AARs obtained for all stations in Europe, the smallest AARs are obtained when the data from the stations of set 1 or set 2 are used for assimilation. The local character of the assimilation is sustained here by the fact that the AAR value obtained using only foreign stations in the assimilation $\left(21.2 \mu \mathrm{g} \mathrm{m}^{-3}\right)$ is better than the AAR value using the seven stations in the Netherlands $\left(26.4 \mu \mathrm{g} \mathrm{m}^{-3}\right)$. The lack of information, for all stations in Europe, in case of using only the stations from the Netherlands in the assimilation is also expressed by the small change in AAR values (from 27.4 to $26.4 \mu \mathrm{g} \mathrm{m}^{-3}$ ) obtained with this assimilation. The same behavior as shown here for the average of the stations in Europe holds also for the individual stations. From these analyses it can be concluded that the combination of the EUROS model and the data assimilation performs well locally, and that the impact of information coming from further away (i.e., in this case foreign sites) is limited (i.e., this case for the Netherlands). This local characteristic of the model can be translated in the local influence of one observation in the assimilation process.

[49] In section 2.3 in the measurement update step the use of independent measurements is important. The small standard deviations from Table 2 compared with the AAR values can be explained by the use of independent measurement and by the number of observations. The fact that the measurements are independent leads to the idea that the system receives new information each time an observation becomes available. This causes the appearance of the small standard deviation. The dependence with the number of observations can be observed in Table 3 . If no measurements are assimilated the standard deviations values are large, at the same level of magnitude as the AAR values for the same case. This is what is expected to happen. If only one Dutch stations is used for assimilation the standard deviations are dropping, but not too much. There is an improvement in the standard deviations for the stations in the Netherlands, but much less for the foreign stations. The use of observational sets 1 or 2 leads to a fast drop in the standard deviation, from 19.2 to 2.2 (or 2.3) for the Dutch stations. The same drop can be observed for the foreign stations and for all stations in Europe. The smallest values appear if both set are used together.

[50] As discussed in section 4.2, the standard deviation in the noise of the observations of ozone was set at $10 \mu \mathrm{g} \mathrm{m}^{-3}$. To test what the effect of this parameter has on the assimilation, simulations were performed with values ranging from 2 to $40 \mu \mathrm{g} \mathrm{m}^{-3}$ for the standard deviation in the noise on the observations. The lowest AAR values were obtained with a noise in the observations of 10 and $20 \mu \mathrm{g} \mathrm{m}^{-3}$. Using larger or smaller values resulted in higher AARs. The data assimilation encounters difficulties when uncertainties in the ozone observations of $2 \mu \mathrm{g} \mathrm{m} \mathrm{m}^{-3}$ or smaller were used, resulting in large AAR values. Those unusual large numbers are due to the fact that the use of
Table 4. Contributions of the Different Model Noise Parameters to the Total AARs After Assimilation for the Average of the Validation Stations in the Netherlands and in Europe, Calculated With the ENKF Algorithm With 20 Modes for 1-30 June $1996^{\text {a }}$

\begin{tabular}{lrrrrrrrr}
\hline & \multicolumn{3}{c}{ Europe } & & \multicolumn{3}{c}{ Netherlands } \\
\cline { 2 - 3 } & Diurnal & Day & Night & & Diurnal & Day & Night \\
\hline EUROS & $0 \%$ & $0 \%$ & $0 \%$ & & $0 \%$ & $0 \%$ & $0 \%$ \\
Noise in $\mathrm{NO}_{\mathrm{x}}$ emissions & $50 \%$ & $46 \%$ & $56 \%$ & & $82 \%$ & $79 \%$ & $85 \%$ \\
Noise in $\mathrm{VOC}^{2}$ emissions & $41 \%$ & $36 \%$ & $48 \%$ & & $43 \%$ & $26 \%$ & $64 \%$ \\
Noise $J\left(\mathrm{NO}_{2}\right)$ & $27 \%$ & $32 \%$ & $19 \%$ & & $40 \%$ & $55 \%$ & $21 \%$ \\
Noise $J\left(\mathrm{O}_{3}\right)$ & $9 \%$ & $-4 \%$ & $30 \%$ & & $-21 \%$ & $-65 \%$ & $33 \%$ \\
Noise in $\mathrm{O}_{3}$ deposition & $9 \%$ & $18 \%$ & $-3 \%$ & & $15 \%$ & $24 \%$ & $5 \%$ \\
Noise in all & $100 \%$ & $100 \%$ & $100 \%$ & $100 \%$ & $100 \%$ & $100 \%$ \\
\hline
\end{tabular}

${ }^{\mathrm{a}}$ The AARs of the EUROS model are set to $0 \%$, and the AARs to which all five noise parameters have been applied are set to $100 \%$. Note that the sum of effects of the individual contributions is not $100 \%$, since effects of noise parameters may compensate for each other.

very accurate observations (i.e., small error in the noise of the observations) leads to large Kalman gain values resulting in instabilities in the approximations of the Kalman filter (equation (9) first equation), i.e., it introduces an unbalance in the update of the state vector. So the value of $10 \mu \mathrm{g} \mathrm{m}^{-3}$ used as a default in this study not only agrees with the value of Flemming et al. [2003] derived on observational grounds, but it also gives "optimal" results for our assimilations.

\subsection{Noise Parameters}

[51] The parameters used for the noise in the model (emissions of $\mathrm{NO}_{\mathrm{x}}$ and VOCs, photolysis rates of $\mathrm{NO}_{2}$ and $\mathrm{O}_{3}$, and deposition of $\mathrm{O}_{3}$ ) affect the performance of the assimilation to a large extent. In this section the contribution of the five noise parameters in the assimilation process are discussed as well as the effect of the size of the model noise parameters, i.e., the standard deviation $\sigma_{a}$ of the noise $w$ and the correlation time length $a$ (color in noise) in equation (20). The values of the noise parameters after the assimilation show what corrections should be made to the EUROS model results to obtain better agreement with the observations.

[52] In Table 4 the relative contributions of the various noise parameters to the total AARs. The contributions shown in Table 4 are relative reductions in AARs, considering that the best improvement can be obtained by applying all noise parameters $(100 \%)$. The largest impact on the assimilation comes from the noise in the emissions of $\mathrm{NO}_{\mathrm{x}}$ and VOCs, which can be about $52 \%$ and $43 \%$ on average, respectively, over all (validation + assimilation) stations. This impact is about the same for the day and at night and somewhat larger in the Netherlands than in Europe as a whole.

[53] The impact of noise on the photolysis rate of $\mathrm{NO}_{2}$ is, averaged over all stations, about $25 \%$, with significantly larger impacts during the day than during the night. Obviously, during the night there is no photolysis, but a perturbation of concentrations during the day has an impact also during the night. Applying only noise in the ozone photolysis rate increases the AAR values in the Netherlands relative to the EUROS calculation. Averaged over all (validation + assimilation) stations in Europe gives a small decrease of $8 \%$ in AARs. Noise in the photolysis 
rates is given as one number for the whole model domain. The decrease in AARs averaged over all European stations and increase in AARs in the Netherlands shows that the effect of the ozone photolysis on the ozone concentration is not homogeneous over the model domain. Closer investigation shows that the diurnal average AARs in all stations below about $48^{\circ} \mathrm{N}$ (in Spain, Switzerland, Italy, and part of Austria) decrease, while the AARs in the majority of the stations above about $48^{\circ} \mathrm{N}$ increase with noise in the photolysis rate of ozone. During the daytime the average AARs are much higher, which for most stations is compensated for by a large decrease in values during the night. This indicates that there might be problem with the modeling of the photolysis in EUROS, causing latitudinal differences in the ozone concentrations. This effect is not seen when noise is introduced in the photolysis rates of $\mathrm{NO}_{2}$, maybe because there are several other reactions involved between the photolysis of $\mathrm{NO}_{2}$ and the formation of ozone, which diminish the effect on the ozone.

[54] Noise in the deposition rate of ozone slightly affects the assimilation, with somewhat larger improvements during the day than during the night.

[55] The effects of the various noise parameters differ for the various stations (variability), but there are no large differences between the validation and assimilation stations.

[56] The best assimilation results for the concentrations are obviously obtained with as many noise parameters as possible, so that one has a lot of flexibility to use the Kalman filter such that one gets close to the observations. However, introducing only noise in the emissions of $\mathrm{NO}_{\mathrm{x}}$ and VOCs and in the photolysis of $\mathrm{NO}_{2}$ the most significant improvements are already obtained. Introducing noise in the photolysis rate in ozone might be useful, especially when defining several regions in latitudinal direction for this parameter, but looking more closely at the modeling of the photolysis in EUROS might be more important. Introducing noise in the deposition rate of ozone gives only small improvements and is hardly worth the additional number of modes and computing time required.

[57] Up to now only the default values for the noise parameters (see section 4.2) have been discussed. The size of these parameters is based on estimates of the uncertainties in the noise parameters of the model. The results obtained for a range of values of the standard deviation and the correlation time length of the noise parameters in assimilations are studied in order to see their impact on the assimilation process. The impact of changing the standard deviation and time correlation length on the AARs values is small, always less than $6 \%$. Closer investigation shows that the characteristics of the noise have a larger impact on the noise factors themselves, after assimilation (noise factors are discussed in section 5.9). The time correlation influences the noise factors; mostly below $25 \%$, with some extreme values above $50 \%$. So, the characteristics of the noise do not influence the AAR values significantly. Firstly, this is because these are averaged values, and secondly, because the effects depend to a large extent on the physics of the model, i.e., on what one can expect the model to deliver. Ozone concentrations are not very sensitive to abrupt changes in emissions or deposition rates. Changes occur on timescales of days or more and the noise parameters have
Table 5. Effect of Model Noise Applied to Various Regions of Europe on the AARs of the Validation Stations in the Netherlands, in the Regions With Noise and in Europe Calculated With the ENKF Algorithm With 20 Modes for 1-30 June 1996 ${ }^{\mathrm{a}}$

\begin{tabular}{lccc}
\hline \multicolumn{1}{c}{ Noise in Regions } & \multicolumn{3}{c}{$\begin{array}{c}\text { Absolute Average } \\
\text { Residuals, } \mu \mathrm{m} \mathrm{m}^{-3}\end{array}$} \\
\cline { 2 - 4 } & $\mathrm{NL}$ & Regions & All \\
\hline EUROS & 26.1 & 26.6 & 27.7 \\
NL + BEL + LUX & 17.3 & 22.0 & 22.7 \\
NL + BEL + LUX, GER + DNK & 17.8 & 20.1 & 21.3 \\
NL + BEL + LUX, GER + DNK, UK + IRL & 17.2 & 19.0 & 20.4 \\
NL + BEL + LUX, GER + DNK, UK + IRL, FR & 17.7 & 19.3 & 20.8 \\
GER + DNK, UK + IRL, FR & 21.4 & 21.5 & 22.2 \\
One region covering all eight countries & 17.6 & 18.9 & 20.7 \\
\hline
\end{tabular}

${ }^{a}$ Regions are defined as the area covering the Netherlands, Belgium (BEL), Luxembourg (LUX), France (FR), Germany (GER), Denmark (DNK), the UK, and Ireland (IRL), i.e., the regions with noise in emissions of $\mathrm{NO}_{\mathrm{x}}$ and VOCs and noise in the deposition rate of $\mathrm{O}_{3}$. In the last row, noise in one region is considered covering all eight countries. Noise was also applied to the photolysis rates here (always in one region)

sufficient time to adapt in this period, also with small standard deviations.

\subsection{Noise Regions}

[58] Simulations were performed using noise in different regions in order to determine which of the regions must be used in the data assimilation process. All the noise specifications are concentrated in the four region defined in section 4.1 for the emissions of $\mathrm{NO}_{\mathrm{x}}$ and VOCs, and for the deposition rate of ozone. The noise in the photolysis rates of $\mathrm{O}_{3}$ and $\mathrm{NO}_{2}$ is applied on the whole EUROS model domain. In the simulations presented in Table 5 the noise for the emissions and deposition was applied to certain limited areas. First the noise was included only in area of the Netherlands, Belgium, and Luxembourg and the AARs were calculated averaged over the all validation stations in the Netherlands, the regions with noise, and in Europe. In the next three simulations the other noise regions were added one by one, introducing noise also for the area of Germany and Denmark, the UK and Ireland, and France. By introducing noise only to the first region (NL + BEL + LUX) yields about the same reduction in AAR values (compared with the EUROS run) for the Netherlands than applying noise to all four regions. Introducing noise to more regions than only $\mathrm{NL}+\mathrm{BEL}+\mathrm{LUX}$ has almost no effect on the AARs in the Netherlands, but does yield a reduction in AARs for all the stations in Europe and for the area with noise (Regions). Furthermore, the AAR values for the Netherlands are getting worse (from $17.3 \mu \mathrm{g} \mathrm{m}^{-3}$ to $21.4 \mu \mathrm{g} \mathrm{m}^{-3}$ ) when the noise is removed from the area of the Netherlands (NL + BEL + LUX) and only applied to the other three regions. The same pattern can be observed if the results are calculated for the Regions or for the whole of Europe. Adding noise to the area of France gives slightly higher AAR values. This is somewhat surprising since the are almost no observations present in France in our assimilation and adding more noise regions gives the assimilation more flexibility which is expected to result in lower AAR values. The last row of Table 5 gives the AAR values for a simulation with noise was considered for one big region covering all four regions (eight countries). The AAR values obtained are almost the same as those obtained using four noise regions. 
[59] These results again show the local character of the data assimilation using the Kalman filter and the EUROS model, i.e., the assimilation works there where noise is applied and has limited effect further away.

\subsection{Assimilated Ozone Concentrations}

[60] In the sensitivity analysis discussed above all interpretations of the results are based on the accuracy of the prediction, expressed by the AAR values. The AAR value is a measure of how much the modeled ozone concentration has been improved with respect to the concentration measured at the measurement site. The model results and the improvements achieved by the assimilation of data can be quantified at the measurement sites, where information about the measured values is available from the observations. This information can then be compared with the KF mean to determine if improvement is achieved. In the case of grid cells where no observations are available, the Kalman filter works as an interpolator that uses the information from the existing observations to estimate the ozone concentration. This means that the information obtained for a grid cell without observations is constrained by the other observations. For example, in France, where almost no observations are present, the information about that region is also changed by the assimilation process. In Figures 8a and $8 \mathrm{~b}$ one can observe that in the grid cells far away from observations and from the noise regions (Norway, Finland and Russia), there are hardly any changes in the concentrations. The geographical position also influences the analysis of the data assimilation process. In the north of Europe, where there are low ozone concentrations anyway, there are almost no changes in the ozone concentrations. In contrast, in the south of Europe (for example in Spain), the ozone concentrations are much higher and the absolute changes are also much larger.

\subsection{Correction Factors for the Noise Parameters}

[61] The noise parameters defined in equations (22), (24), and (25), can be interpreted as correction factors. They are the factors that represent the corrections to the EUROS model at every time step after the analysis of the Kalman filter mean (equation (9)). Their implementation in the data assimilation process is a multiplicative one. These factors depend on the quality of the EUROS model. The values for the noise factors have been bounded between 0.2 and 5 (multiplication factors) in order to prevent unrealistic variations in the model input and instabilities in the model simulations. In Figure 9 the noise factors are plotted for the emissions of $\mathrm{NO}_{\mathrm{x}}$ (Figure 9a), emissions of VOCs (Figure 9b), the photolysis rates of $\mathrm{NO}_{2}$ (Figure 9c) and $\mathrm{O}_{3}$ (Figure 9d), and the deposition rate of $\mathrm{O}_{3}$ (Figure 9e). All panels show a large hourly variability in the noise factors (see also Table 6). This is caused by the instantaneous prediction of the Kalman filter from one step to the next. The effect of an emission of $\mathrm{NO}_{\mathrm{x}}$ and VOCs on the ozone

Figure 8. Concentration of ozone $\left(\mu \mathrm{g} \mathrm{m}^{-3}\right)$ at the observation height in Europe for 6 June 1996, 1500 UT, based on (a) an EUROS model run, (b) an assimilation with the ENKF algorithm with 20 modes, and (c) the difference (EUROS - KF mean). a) Euros model run

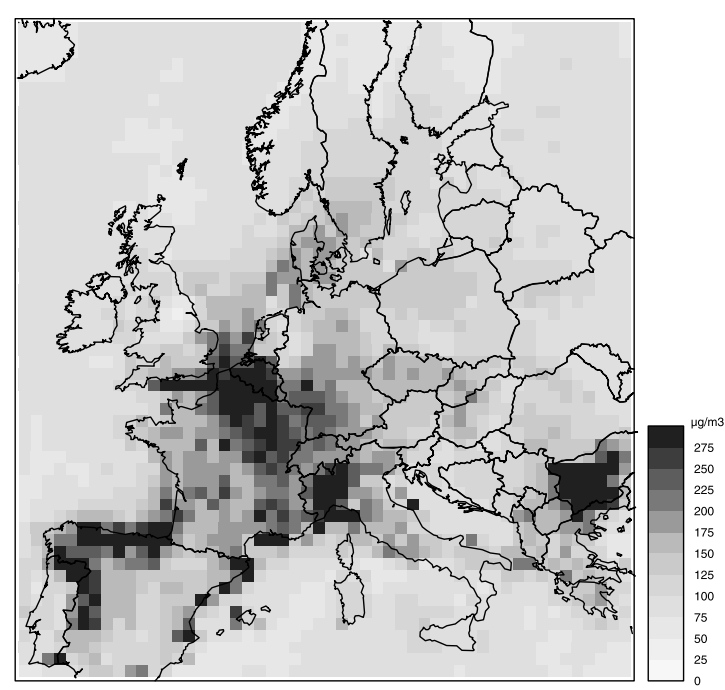

b) KF mean

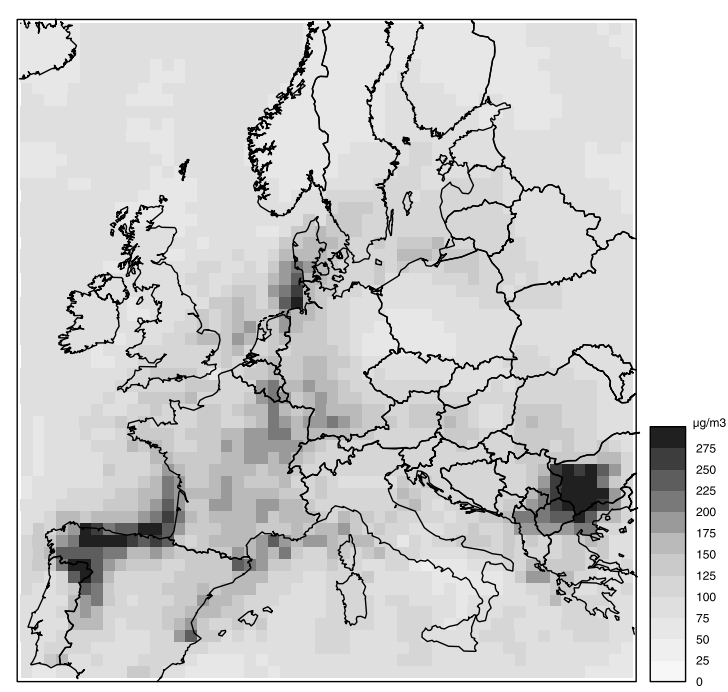

c) Euros - KF mean

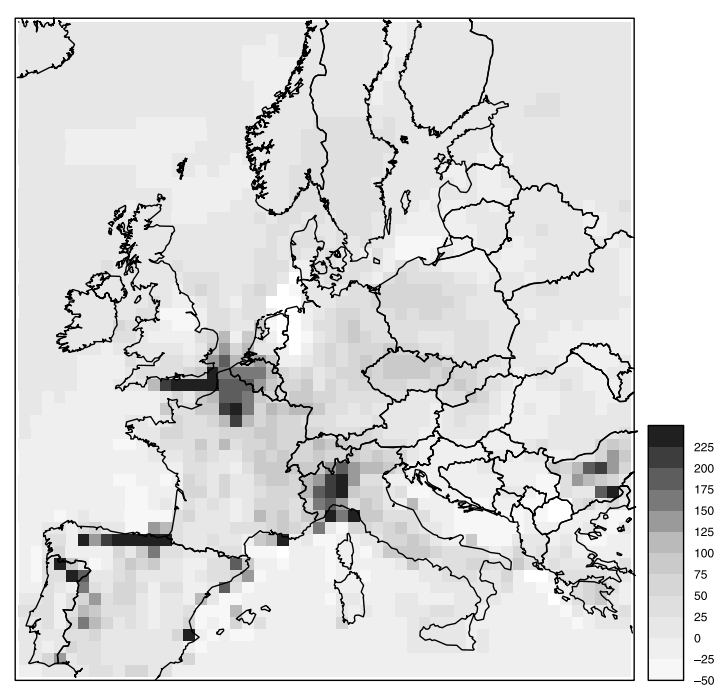


(a) Noise factor for emissions of NOx

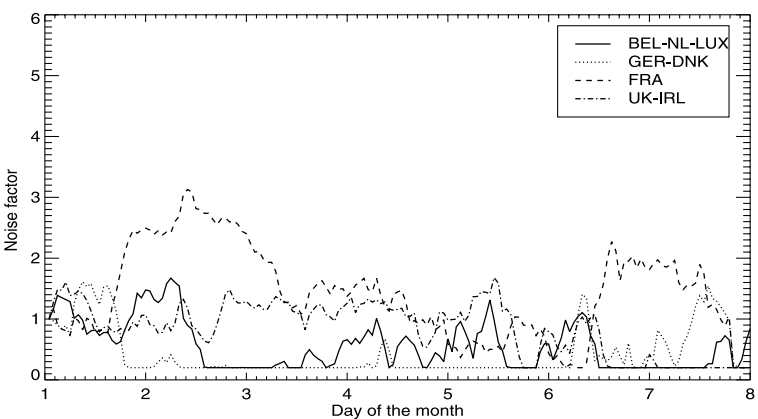

(b) Noise factor for emissions of VOC

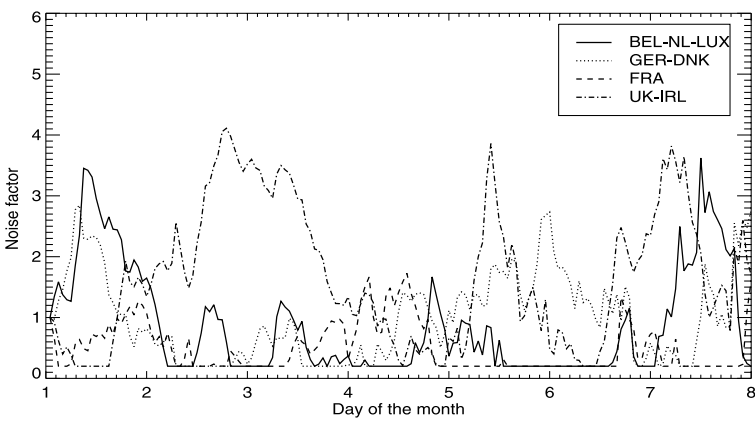

(c) Noise factor for photolysis rate of $\mathrm{NO2}$

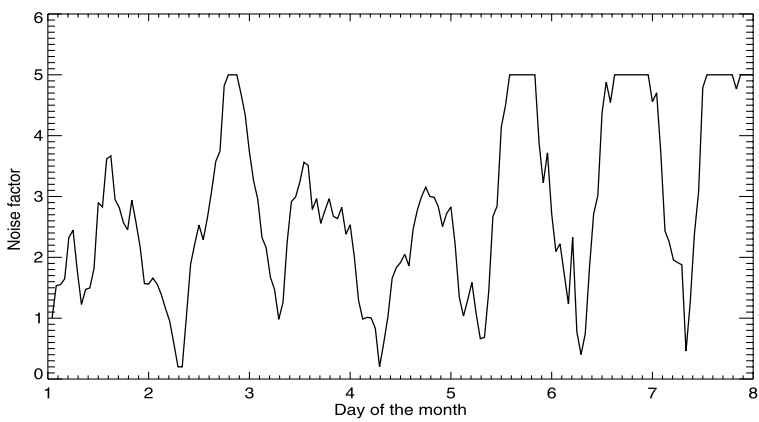

(d) Noise factor for photolysis rate of ozone

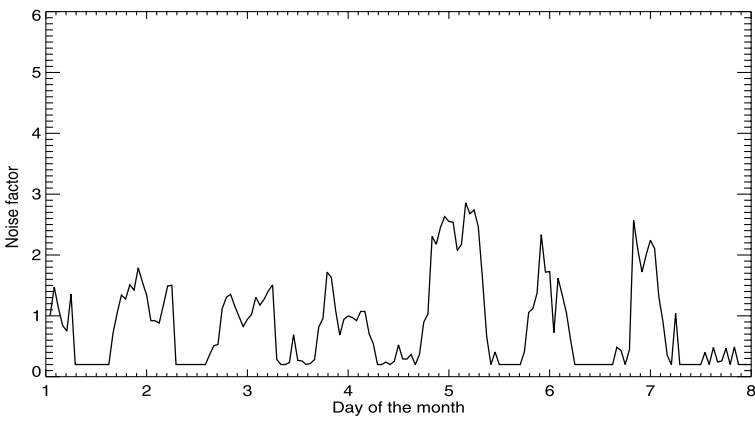

(e) Noise factor for deposition of ozone

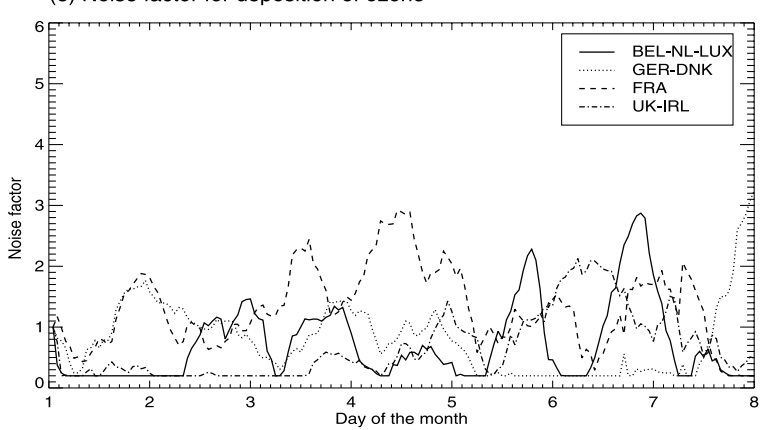

Table 6. Monthly Average Noise Factors Calculated With the ENKF Algorithm With 20 Modes for 1-30 June 1996 ${ }^{\mathrm{a}}$

\begin{tabular}{|c|c|c|c|c|}
\hline & $\begin{array}{c}\text { BEL + NL } \\
\quad+\text { LUX }\end{array}$ & GER + DNK & FRA & $\mathrm{UK}+\mathrm{IRL}$ \\
\hline Emissions $\mathrm{NO}_{\mathrm{x}}$ & $0.66(0.15)$ & $0.48(0.15)$ & $1.06(0.16)$ & $0.73(0.15)$ \\
\hline Emissions VOC & $0.89(0.28)$ & $1.63(0.28)$ & $0.81(0.27)$ & $1.46(0.29)$ \\
\hline Photolysis $\mathrm{NO}_{2}$ & $2.77(0.36)$ & & & \\
\hline Photolysis $\mathrm{O}_{3}$ & $0.50(0.32)$ & & & \\
\hline Deposition $\mathrm{O}_{3}$ & $0.84(0.12)$ & $1.70(0.13)$ & $1.00(0.13)$ & $0.97(0.13)$ \\
\hline
\end{tabular}

concentrations is spread out over hours or days. In this period the species are transported over hundreds of kilometers and are being affected by chemical reactions. These periods are in general longer than half an hour, i.e., longer than the time step between two observations and the time step for the Kalman filter to adjust the noise parameters. Therefore large noise factors are necessary to obtain the change in the ozone concentrations at every time step. For this reason these factors should be considered as corrections to the EUROS model, not as improvement factors for emissions. A Kalman filter smoother can be used to overcome this problem.

[62] Looking at Figures $9 \mathrm{a}$ and $9 \mathrm{~b}$, it seems that the variation of the correction factors is larger for VOC than for $\mathrm{NO}_{\mathrm{x}}$ emissions. This is probably caused by the different response of the ozone chemistry to these emissions.

[63] Large noise factors can be seen for France in Figures 9a and 9e. As has been discussed before, the assimilation has its largest impacts close to the regions where noise is applied. Consequently, because of the lack of observations on ozone in France (there is only one station close to the Belgium border in the databases) the noise factors for the region of France are hardly able to affect the ozone concentrations at the measurement stations used for this region. Therefore these factors can take almost any value without having a direct affect on the AAR values. Also, a large noise factor for $\mathrm{NO}_{\mathrm{x}}$ emissions at one time step resulting in a large emission transported over the borders of the region of France will be compensated for by smaller noise factors in other regions.

[64] The noise factors of the photolysis rates (Figures 9c and 9d) show a clear diurnal cycle. Since there is no photolysis during the night, the nighttime values for the noise factors of the photolysis rates have no physical meaning. Even though the noise factors show a large variability, the difference between the monthly average factors are in most cases not so large (see Table 6). There is a variation from 0.48 to 1.06 and from 0.81 to 1.63 for the emissions of $\mathrm{NO}_{\mathrm{x}}$ and VOCs, respectively, and from 0.84 to 1.70 for the deposition rate of ozone. The monthly average factor for the photolysis rate of $\mathrm{NO}_{2}$ is much larger (2.77), while that of $\mathrm{O}_{3}$ is only 0.50 . Clearly, there are more direct and better ways to improve photolysis rates used in an atmosphere model than assimilation of chemical constitu-

Figure 9. Correction factors of noise specifications obtained by the ENKF algorithm with 20 modes for the period 1-7 July 1996. The noise factor for (a) emissions of $\mathrm{NO}_{\mathrm{x}}$, (b) emissions of VOC, (c) photolysis rate of $\mathrm{NO}_{2}$, (d) photolysis rate of ozone, and (e) deposition of ozone. 
ents, i.e., the use of meteorological observations, cloud cover data, etc. This not only requires a considerable effort, but is also outside the scope of this paper. Noise is applied to photolysis rates to obtain optimal ozone concentrations and the correction factors are shown here merely as an output of the assimilation and should not be interpreted as new physical parameters for photolysis.

[65] The noise parameters may influence each other when applied simultaneously. The presence or absence of one of them may change all the values. It can be observed that the variability of each noise parameter is almost the same for all the regions. For example, for Germany, high noise factor values were applied in comparison with the other regions to reflect the measured values. The values of the correction factors depend also on the EUROS model. The noise parameters are "optimal" within the constraints of the model and the observations used in the assimilation. Since there is the risk of correcting certain parameters for the wrong reasons considerable attention should be paid to the interpretation of these optimized noise parameters.

[66] In the current implementation all species are part of the state vector (equation (20)) in the assimilation. In this study the emissions of $\mathrm{NO}_{\mathrm{x}}$ and VOCs are defined as uncertain parameters in the calculation and the Kalman filter adapts them to minimize the difference in ozone concentration between the filter mean and the EUROS model. Consequently, the concentrations of $\mathrm{NO}$ and $\mathrm{NO}_{2}$, and VOCs are also changed by the model. Also, the magnitude of the changes in emissions and in concentrations of $\mathrm{NO}$ and $\mathrm{NO}_{2}$, and VOCs depends on the quality of the EUROS model.

\section{Conclusions}

[67] The work described here has laid the foundation for research on data assimilation with a Kalman filter, the EUROS model and ground-based or satellite observations for various atmospheric trace gases (ozone, $\mathrm{NO}_{\mathrm{x}}, \mathrm{SO}_{2}, \mathrm{CO}$ and $\mathrm{CH}_{4}$ ). We have shown data assimilation using a Kalman filter in combination with the atmospheric chemistry transport model EUROS to be successful, giving more accurate results for boundary layer ozone than the EUROS model or measurements separately. Average residuals decreased from 26.4 to $17.5 \mathrm{\mu g} \mathrm{m}^{-3}$ for the validation stations in the Netherlands and from 27.4 to $20.5 \mu \mathrm{g} \mathrm{m}^{-3}$ for the average of all validation stations in Europe. Because of the large number of stations with ozone observations in relation to the number of noise parameters, the assimilation gave similar results for the stations used in the assimilation to those used only for validation purposes.

[68] The accuracy of the data assimilation increases with an increasing number of modes. In general, the difference between the assimilated and measured ozone concentrations using the RRSQRT algorithm is lower using a small number of modes (about 10) than employing the ENKF algorithm. Both algorithms tend to converge to about the same accuracy with an increasing number of modes. The greatest improvements were obtained using 80 modes, but great improvements had already been obtained with only 10 modes, for both the RRSQRT and the ENKF algorithms. Therefore, taking into account that computation time increases with the number of modes, the use of $10-$
20 modes would seem sufficient for this application in atmospheric modeling. This is confirmed by comparing the average standard deviation of the residuals from a set of ensemble simulations with the square root of the covariance matrix after an assimilation (see Table 2). The ENKF algorithm seems to perform slightly better than the RRSQRT algorithm for a nonlinear system, such as the one used here (i.e., yielding smaller differences in observations with a small number of modes).

[69] The uncertainties in the $\mathrm{NO}_{\mathrm{x}}$ and VOCs emissions and the photolysis rate of $\mathrm{NO}_{2}$ had the largest impact on the ozone assimilation in the model. Applied individually, noise specifications in $\mathrm{NO}_{\mathrm{x}}$ emissions, and $\mathrm{VOC}$ and photolysis of $\mathrm{NO}_{2}$, contribute $50 \%, 41 \%$, and $27 \%$, respectively, to the total reduction in average residuals for Europe, where all five noise parameters are applied simultaneously. The choice of the uncertainty in the noise input parameters, i.e., standard deviation and time correlation length of the noise, is made on the basis of prior knowledge on the quality of these parameters. Changing the standard deviation and time correlation length has been shown to only slightly affect the difference between assimilated and measured ozone concentrations, but to definitely affect the noise value after assimilation.

[70] The uncertainty in the ozone observations is set at $10 \mu \mathrm{g} \mathrm{m}^{-3}$ on the basis of studying the error covariances of a set of observations by Flemming et al. [2003]. The use of different uncertainties ranging from 5 to $40 \mu \mathrm{g} \mathrm{m}^{-3}$ yields about the same results, but for values lower than $5 \mu \mathrm{g} \mathrm{m}^{-3}$ the yield is inconsistent because of instabilities in the assimilation.

[71] Analyses of several simulations showed the assimilation to reflect a local character. First, when a large number of observations are assimilated, their effect on the ozone concentration remains confined to the area close to the observations. However, when only a few observations are used, they affect a much larger area. Second, the noise applied to $\mathrm{NO}_{\mathrm{x}}$ and VOC emissions in certain regions of Europe has its main effect on the ozone concentrations in the specific region where the noise is applied. Where there is only one region, the effect of the noise will cover an area larger than the region. In the current implementation of the Kalman filter, not only are the concentrations of trace gases assimilated, but also the noise parameters, i.e., $\mathrm{NO}_{\mathrm{x}}$ and VOC emissions, the photolysis rates of ozone and $\mathrm{NO}_{2}$ and the deposition rate of ozone. These concentrations and noise parameters all form part of the state vector, making it possible to find the optimum values for the noise parameters (e.g., emissions), given the chemical and physical properties, as prescribed by the EUROS model, and given the observations of ozone.

[72] In the work described here, we have not concentrated on the noise parameters as output of the assimilation. This will be a subject of further research. A first analysis of these noise parameters shows large hourly variability for all parameters, caused by the instantaneous prediction of the Kalman filter from one step to the next. Therefore large noise factors are necessary to obtain the change in the ozone concentrations in every time step. Even though noise shows great variability, the monthly average factors are not so large, i.e., between 0.5 and 1.7 , for most parameters. The noise parameters may influence each other when applied 
simultaneously. The presence or absence of one of them may change all the values. Also, these factors also depend on the quality of the EUROS model. Noise parameters may attempt to compensate for unknown errors in the model. The noise parameter values may also be additionally constrained by different measurements. Assimilating ozone and $\mathrm{NO}_{\mathrm{x}}$ measurements simultaneously will considerably affect the emissions of $\mathrm{NO}_{x}$ as noise parameter.

[73] Ensemble filters have been used more often the last few years and new algorithms are being developed. New developments include the deterministic Kalman filter ensemble, with no noise forcing in the observations at every time step [Whitaker and Hamill, 2002]; the adjusted Kalman filter ensemble, based on the inflation of the error covariance matrix at every time step with a parameter that changes online (depending on the background error covariance [Anderson, 2001]); the adaptive Kalman filter ensemble, where an adaptive technique for estimating model error is used [Mitchell and Houtekamer, 2000] and the sequential Kalman filter ensemble, based on an efficient implementation of the analysis step [Houtekamer and Mitchell, 2001]. Another new development is the construction of hybrid algorithms, in which two algorithms are linked to obtain better estimations by making use of the best parts of both algorithms, as in the Partial Orthogonal ensemble Kalman filter (POENKF) and the Complementary Orthogonal subspace Filter For Efficient Ensembles (COFFEE) [Heemink et al., 2001]. The performance of these new algorithms with respect to the assimilation of ozone and $\mathrm{NO}_{\mathrm{x}}$ will be subject of further research.

[74] Acknowledgments. We would like to thank Arjo Segers of KNMI and Ferd Sauter of RIVM for support with the simulations and the computer code and Martin Verlaan of TUD for useful theoretical and practical discussions.

\section{References}

Anderson, J. L. (2001), An ensemble adjustment Kalman filter for data assimilation, Mon. Weather Rev., 129, 2884-2903.

Canizares, R. (1999), On the application of data assimilation in regional costal models, Ph.D. thesis, Delft Univ. of Technol., Delft, Netherlands.

Cohn, S. E., and R. Todling (1995), Approximate data assimilation schemes for stable and unstable dynamics, J. Meteorol. Soc. Jpn., 74, 63-75.

Courtier, P., J. Derber, R. Errico, J.-F. Louis, and T. Vukićević (1993), Important literature on the use of adjoint, variational methods and the Kalman filter in meteorology, Tellus, Ser. A, 45, 342-357.

Dee, D. P. (1991), Simplification of the Kalman filter for meteorological data assimilation, Q. J. R. Meteorol. Soc., 117, 365-384.

Elbern, H., H. Schmidt, and A. Ebel (1997), Variational data assimilation for tropospheric chemistry modeling, J. Geophys. Res., 102, 15,96715,985 .

Elbern, H., H. Schmidt, O. Talagrand, and A. Ebel (2000), 4D-variational data assimilation with an adjoint air quality model for emission analysis, Environ. Modell. Software, 15, 539-548.

Elzakker, B. G. (2001), Monitoring activities in the Dutch National Air Quality Monitoring Network, RIVM Rep. 723101055, Natl. Inst. of Public Health and the Environ., Bilthoven, Netherlands.

European Communities (EC) (1996), Council directive 96/62/EC of 27 September 1996 on ambient air quality assessment and management from EU Air Quality Framework Directive, Off. J. Eur. Commun., L, Legis., 296, 21/11/1996, 55-63.

Evensen, G. (1994), Sequential data assimilation with a nonlinear quasigeostrophic model using Monte Carlo methods to forecast error statistics, J. Geophys. Res., 99, 10,143-10,162.

Evensen, G., and P. J. van Leeuwen (1996), Assimilation of Geosat altimeter data for the Agulhas current using ensemble Kalman filter with quasi-geostrophic model, Mon. Weather Rev., 124, 85-96.

Flemming, J., M. van Loon, and R. Stern (2003), Data assimilation for CTM based on optimum interpolation and Kalman filter, paper presented at 26th NATO/CCMS International Technical Meeting on Air Pollution
Modeling and Its Application, NATO Comm. on the Challenges of the Mod. Soc., Istanbul.

Gery, M. W., G. Z. Whitten, J. P. Killius, and M. C. Dodge (1989), A photochemical mechanism for urban and regional scale computer modeling, J. Geophys. Res., 94, 12,925-12,956.

Ghil, M., and P. Malanotte-Rizzoli (1991), Data assimilation in meteorology and oceanography, Adv. Geophys., 33, 141-266.

Ghil, M., S. Cohn, J. Tavantzis, K. Bube, and E. Isaacson (1981), Applications of estimation theory to numerical weather prediction, in Dynamic Meteorology: Data Assimilation Methods, pp. 139-224, Springer-Verlag, New York.

Hammingh, P., H. Thè, F. de Leeuw, F. Sauter, A. van Pul, and J. Matthijsen (2001), A comparison of three simplified chemical mechanisms for tropospheric ozone modeling, in Transport and Chemical Transformation in the Troposphere: Proceedings of EUROTRAC Symposium 2000, Garmisch-Partenkirchen, Germany, 27-31 March 2000, edited by P. M. Midgley, M. Reuther, and M. Williams, pp. 836-840, SpringerVerlag, New York.

Heemink, A., and H. Kloosterhuis (1990), Data assimilation for non-linear tidal models, Int. J. Numer. Methods Fluids, 11, 1097-1112.

Heemink, A., M. Verlaan, and A. Segers (2001), Variance reduced ensemble Kalman filtering, Mon. Weather Rev., 129, 1718-1728.

Hollingsworth, A., and P. Lönnberg (1986), The statistical structure of short-range forecast errors as determined from radiosonde data, Part I: The wind fields, Tellus, Ser. A, 38, 111-136.

Houtekamer, P., and H. L. Mitchell (1998), Data assimilation using an ensemble Kalman filter technique, Mon. Weather Rev., 126, 796-811.

Houtekamer, P., and H. L. Mitchell (2001), A sequential ensemble Kalman filter for atmospheric data assimilation, Mon. Weather Rev., 129, $123-$ 137.

Lelieveld, J., et al. (2002), Global air pollution crossroads over the Mediterranean, Science, 298, 794-799.

Matthijsen, J., L. Delobbe, F. Sauter, and L. de Waal (2001), Changes of surface ozone over Europe upon the Gothenburg protocol abatement of 1990 reference emissions, in Transport and Chemical Transformation in the Troposphere: Proceedings of EUROTRAC Symposium 2000, Garmisch-Partenkirchen, Germany, 27-31 March 2000, edited by P. M. Midgley, M. Reuther, and M. Williams, pp. 1384-1388, Springer-Verlag, New York.

Maybeck, P. S. (1979), Stochastic Models, Estimation, and Control, Math. Sci. Eng., vol. 141-1, 374 pp., Academic, San Diego, Calif.

Mitchell, H. L., and P. Houtekamer (2000), An adaptive ensemble Kalman filter, Mon. Weather Rev., 128, 416-433.

Pham, D. T., J. Verron, and M. C. Roubau (1998), A singular evolutive extended Kalman filter for data assimilation in oceanography, J. Mar. Syst., 16, 323-340.

Segers, A. (2002), Data assimilation in atmospheric chemistry models using Kalman filtering, Ph.D. thesis, Delft Univ. of Technology, Delft, Netherlands.

Segers, A., A. Heemink, M. Verlaan, and M. van Loon (2000), A modified RRSQRT-filter for assimilating data in atmospheric chemistry models, Environ. Modell. Software, 15, 663-671.

Simpson, D., A. Guenther, C. N. Hewitt, and R. Steinbrecher (1995), Biogenic emissions in Europe: 1. Estimates and uncertainties, J. Geophys. Res., 100, 2875-2890.

Stedman, J. R., and M. L. Williams (1991), A trajectory model of the relationship between ozone and precursors emissions, Atmos. Environ., Part A, 26, 1271-1281.

Talagrand, O., and P. Courtier (1987), Variational assimilation of meteorological observations with the adjoint vorticity equation, I. Theory, $Q$. J. R. Meteorol. Soc., 113, 1311-1328.

Thompson, A. M., and R. W. Stewart (1991), Effect of chemical kinetics uncertainties on calculated constituents in a tropospheric photochemical model, J. Geophys. Res., 96, 13,089-13,108.

van Loon, M. (1996), Numerical methods in smog prediction, Ph.D. thesis, Univ. of Amsterdam, Amsterdam.

van Loon, M., and A. W. Heemink (1997), Kalman filtering for nonlinear atmospheric chemistry models: First experiment, Rep. MAS-R9711, Cent. voor Wiskunde en Inf., Amsterdam.

van Pul, W. A. J., J. A. van Jaarsveld, and C. M. J. Jacobs (1996), Deposition of persistent organic pollutants over Europe, in Air Pollution Modeling and Its Application XI, edited by S. E. Gryning and F. A. Schiermeier, pp. 203-212, Plenum, New York.

van Rheineck Leyssius, H. J., F. A. A. M. de Leeuw, and B. H. Kessenboom (1990), A regional scale model for the calculation of episodic concentrations and depositions of acidifying components, Water Air Soil Pollut., 51, $327-344$.

Velders, G. J. M., J. Matthijsen, M. van Loon, R. van Oss, F. Sauter, and A. Segers (2001), Smog forecasts with a chemistry transport model using data assimilation: Possibilities of GOME tropospheric ozone 
observations, NRSP-2 Rep. 00-38, Natl. Remote Sens. Programme, Delft, Netherlands.

Verlaan, M. (1998), Efficient Kalman filtering algorithms for hydrodynamical models, Ph.D. thesis, Delft Univ. of Technology, Delft, Netherlands.

Verlaan, M., and A. W. Heemink (1995), Reduced rank square root filters for large scale data assimilation problems, paper presented at Second International Symposium on Assimilation of Observations in Meteorology and Oceanography, World Meteorol. Organ., Tokyo.

Verlaan, M., and A. W. Heemink (1996), Data assimilation schemes for non-linear shallow water flow models, Adv. Fluid Mech., 96, 277-286.

Wang, K. Y., D. J. Lary, D. E. Shallcross, S. M. Hall, and J. A. Pyle (2001), A review on the use of the adjoint method in four-dimensional atmospheric-chemistry data assimilation, Q. J. R. Meteorol. Soc., 127, $2181-$ 2204.
Whitaker, J. S., and T. M. Hamill (2002), Ensemble data assimilation without perturbed observations, Mon. Weather. Rev., 130, 1913-1924.

Zhang, X. F., and A. W. Heemink (1995), Data assimilation in transport models, Appl. Math. Modell., 21, 2-14.

Zhang, X. F., A. W. Heemink, L. H. J. M. Janssen, P. H. M. Janssen, and F. J. Sauter (1999), A computationally efficient Kalman smoother for the evaluation of the $\mathrm{CH} 4$ budget in Europe, Appl. Math. Modell., 23, $109-129$.

R. G. Hanea and A. Heemink, Delft University of Technology, P.O. Box 5031, NL-2600 GA Delft, Netherlands. (r.g.hanea@its.tudelft.nl)

G. J. M. Velders, Netherlands Environmental Assessment Agency, RIVM, P.O. Box 1, NL-3720 BA Bilthoven, Netherlands. 